\title{
Impact of Synchronised Flow in Oversat- urated City Traffic on Energy Efficiency of Conventional and Electrical Vehicles
}

\author{
Peter Hemmerle $^{1}$. Micha Koller ${ }^{1}$. Gerhard Hermanns ${ }^{2}$. \\ Hubert Rehborn ${ }^{1}$. Boris S. Kerner ${ }^{2}$. Michael Schreckenberg ${ }^{2}$ \\ ${ }^{1}$ Daimler AG, Sindelfingen, Germany, \\ E-mail: p.hemmerle@gmx.de,(micha.koller,hubert.rehborn)@daimler.com \\ 2 Universität Duisburg-Essen, Physik von Transport und Verkehr, Duisburg, Germany, \\ E-mail: (gerhard.hermanns,boris.kerner,michael.schreckenberg)@uni-due.de
}

Received: 26 May 2016 / Accepted: 12 October 2016

DOI: $10.17815 / C D .2016 .7$

\begin{abstract}
In this study of city traffic, we show that empirical synchronised flow patterns, which have been revealed recently in oversaturated traffic, exhibit considerable impact on the energy efficiency of vehicles. In particular, we have found out that energy consumption in oversaturated city traffic can decrease considerably when the oversaturated city traffic consists of synchronised flow patterns rather than consisting of moving queues of the classical traffic flow theory at traffic signals. Using empirical GNSS data measured by navigation devices on two different road sections in Düsseldorf, Germany, we show that synchronised flow patterns and moving queues differ in their cumulated vehicle acceleration (a sum of positive speed differences along a vehicle trajectory) despite similar mean speeds. Energy efficiency in return is dependent on the cumulated vehicle acceleration. We consider both the fuel consumption of conventional vehicles with combustion engines and the energy balance of electrical vehicles.
\end{abstract}

Keywords Vehicles $\cdot$ city traffic $\cdot$ empirical traffic patterns $\cdot$ synchronised flow $\cdot$ energy efficiency 


\section{Introduction}

City traffic is controlled by traffic signals. It is generally assumed that no significant phenomena of self-organisation occur in city traffic [1-21]. This is because these phenomena are thought to be suppressed by the traffic signals which interrupt traffic flow.

On the other hand, phenomena of self-organisation are well-known to exist in highway traffic. Many of these phenomena are associated with synchronised flow. Synchronised flow is known to be one of the three traffic phases in Kerner's three-phase theory of traffic [22-26]. The three phases are:

1. Free flow.

2. Synchronised flow.

3. Wide moving jams.

Congested highway traffic is subdivided into the synchronised flow phase and the wide moving jam phase. However, synchronised flow also occurs in city traffic: As has recently been found in the three-phase theory of city traffic [27-31], the transition from under- to oversaturated traffic at a traffic signal is associated with the emergence of a synchronised flow pattern in an initially free flow. Furthermore, synchronised flow patterns (SPs) have been predicted to exist in oversaturated city traffic at traffic signals as well [32].

The existence of SPs in real oversaturated city traffic has been confirmed by an empirical analysis of field GNSS (global navigation satellite system) data measured by navigation devices in vehicles [33]. It has been revealed that oversaturated city traffic after speed breakdown consists of SPs, sequences of moving queues (MQs) corresponding to the classical theory of city traffic [1-21] and mixtures of these two spatiotemporal traffic patterns.

SPs in oversaturated city traffic exhibit considerable impact on the fuel consumption of conventional vehicles with a combustion engine [34]. In this paper, we study the impact of SPs in oversaturated city traffic on the energy efficiency of vehicles, addressing both conventional vehicles with a combustion engine and electrical vehicles. We discuss the application of our results to energy-efficient route guidance.

This article is organised as follows. In Sec. 2, we discuss empirical examples of SPs and MQs, which are the basic spatiotemporal traffic patterns in oversaturated city traffic after speed breakdown. In Sec. 3, we describe our approach to estimating the energyefficiency of vehicles depending on the traffic situation. This approach takes into account the cumulated vehicle acceleration, a macroscopic parameter for the assessment of the energy efficiency of vehicles depending on their driving behaviour. In Sec. 4, we sketch the application of the macroscopic energy matrices to energy-efficient route guidance. We discuss macroscopic energy matrices which express the energy efficiency of vehicles in dependency of their mean speed and cumulated acceleration. By means of hypothetical examples, we demonstrate how the fastest route between two points in a route network can be different from the most energy-efficient route. We also show that the most energyefficient route for conventional vehicles can be different from the most energy-efficient route for electrical vehicles. Finally, in Sec. 5, we draw the conclusions. 


\section{Empirical synchronised flow patterns in oversaturated city traffic}

\subsection{Probe vehicle data}

For the study of spatiotemporal traffic patterns in oversaturated city traffic we use anonymised GNSS probe data measured by navigation devices in vehicles provided by the company TomTom. The data set consists of GNSS data from several selected days from 20112014. A navigation device measures the GNSS locations of the vehicle at time instants $t_{n}$ with a fixed time interval $\Delta t=t_{n+1}-t_{n}$ between GNSS measurements. In on-line applications, $\Delta T=5 \mathrm{~s}$ is commonly used.

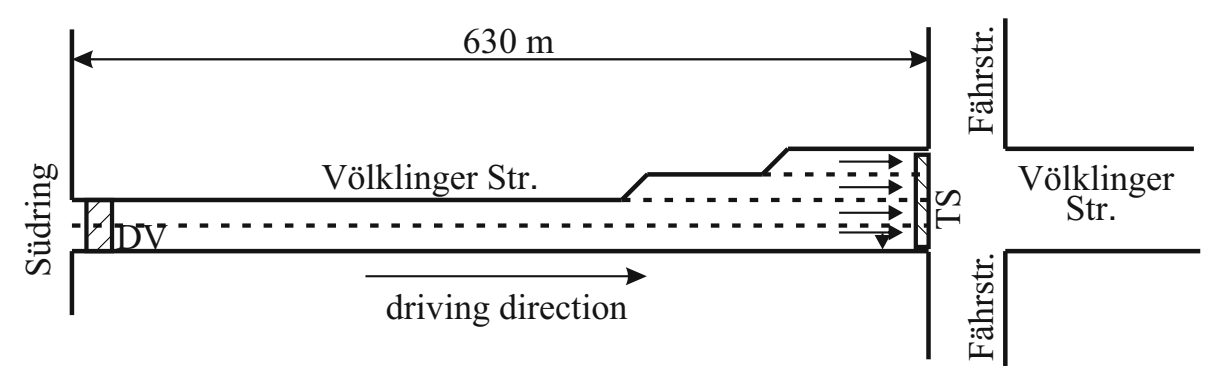

Figure 1 Scheme of the considered section of the roads section "Völklinger Straße". "TS" indicates a traffic signal, "DV" indicates a stationary road detector.

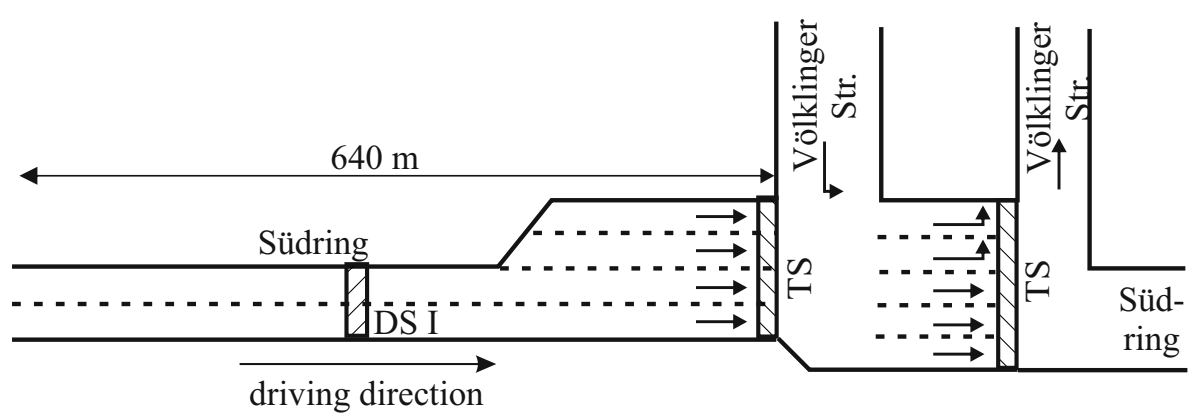

(a) "Südring I"

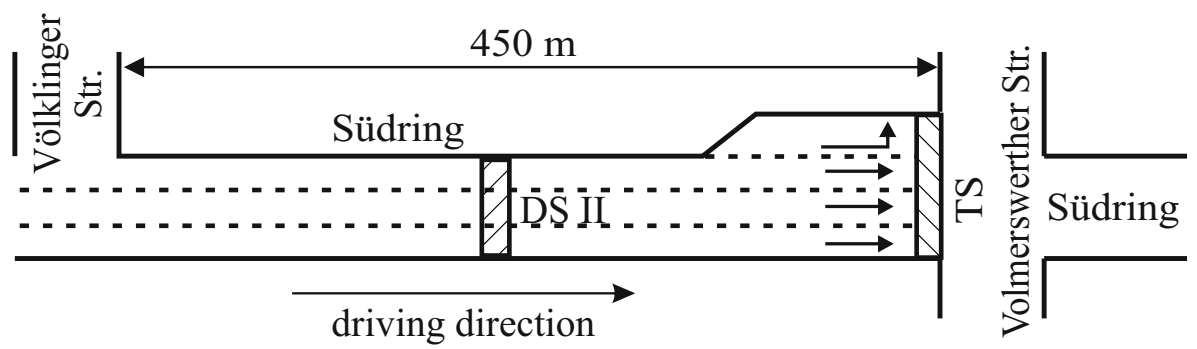

(b) "Südring II"

Figure 2 Schemes of the considered road sections of the road "Südring I". "TS" indicates a traffic signal, "DSI" and "DSII" indicate stationary road detectors. 


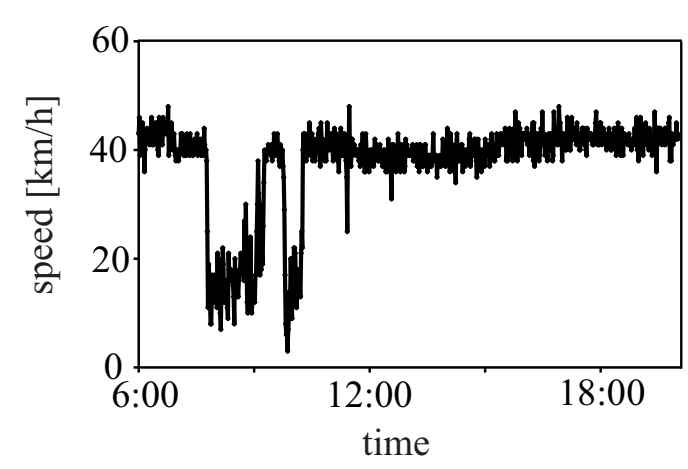

(a) Völklinger Straße, April 10, 2013, 06:0020:00: speed

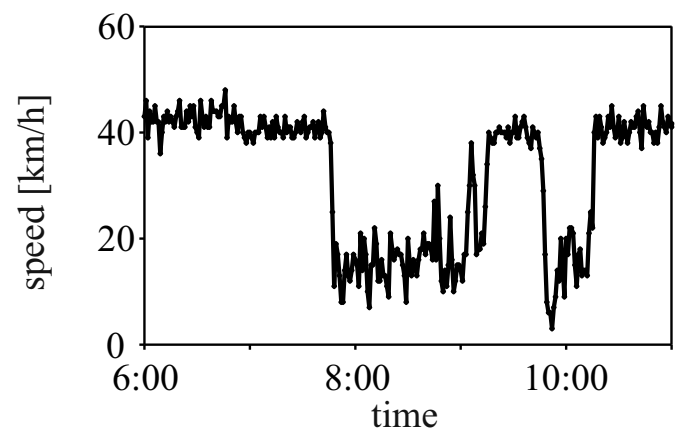

(c) Völklinger Straße, April 10, 2013, 06:0011:00: speed

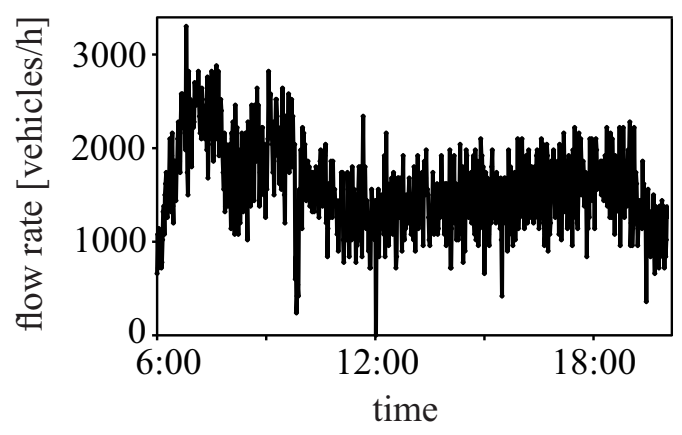

(b) Völklinger Straße, April 10, 2013, 06:0020:00: flow rate

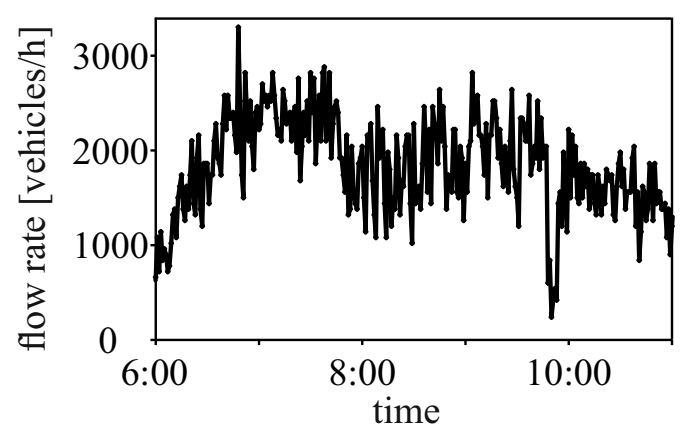

(d) Völklinger Straße, April 10, 2013, 06:0011:00: flow rate

Figure 3 Typical city traffic detector data (I): average speed and total flow rate across two-lane road measured by the stationary detector marked "DV" in Fig. 1. Data of a whole day $(a, b)$ and five-hour excerpt including traffic breakdowns.

We consider three road sections in the city of Düsseldorf, Germany (compare Fig. 1): a $630 \mathrm{~m}$ long section of Völklinger Straße and two sections of Südring (640 m and $45 \mathrm{~m}$ length; we refer to as "Südring I" and "Südring II", respectively). The speed limit on "Völklinger Straße" and "Südring II" is $60 \mathrm{~km} / \mathrm{h}$; on "Südring I" there is a speed limit of $80 \mathrm{~km} / \mathrm{h}$ on the first downstream $250 \mathrm{~m}$ of the section and $60 \mathrm{~km} / \mathrm{h}$ elsewhere. There is a traffic signal at the downstream end of the considered road sections and no traffic signals between their upstream and downstream ends. Furthermore, in addition to the GNSS probe data from navigation devices, aggregated data of average speed and flow rate measured by stationary detectors are available for all three sections. Measurements with these traffic detectors, which we will discuss in Sec. 2.2, confirm that on these road stretches oversaturated traffic occurs on many days [33]. GNSS data was chosen from days on which oversaturated traffic was observed in the detector data.

\subsection{Speed breakdown}

In city traffic at a traffic signal, a traffic breakdown is a transition from undersaturated traffic to oversaturated traffic. The following time patterns, which are well-known from 


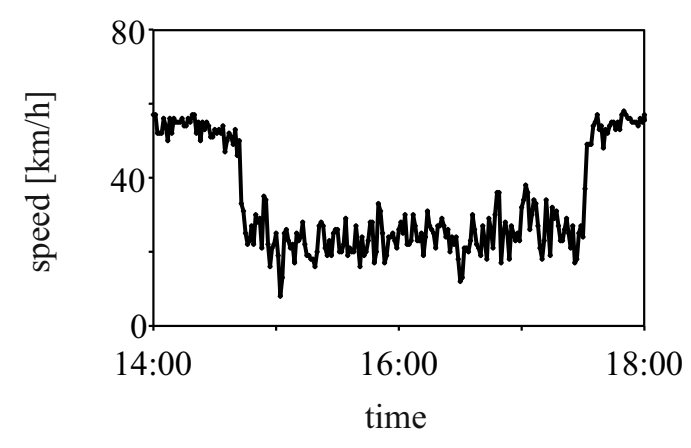

(a) “Südring I", April 12, 2013: speed

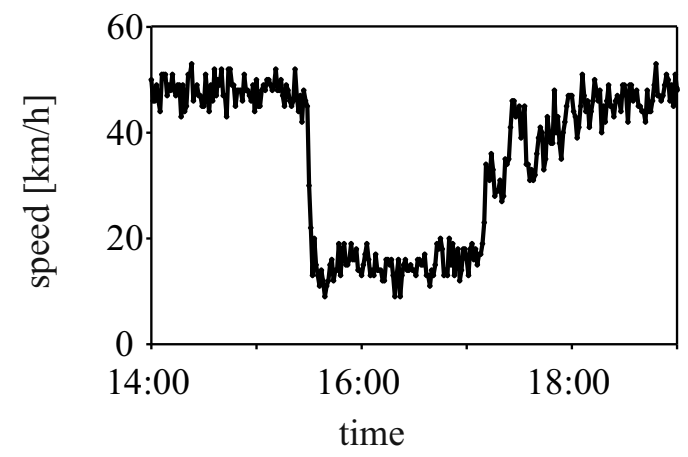

(c) “Südring II", Jan 16, 2013: speed

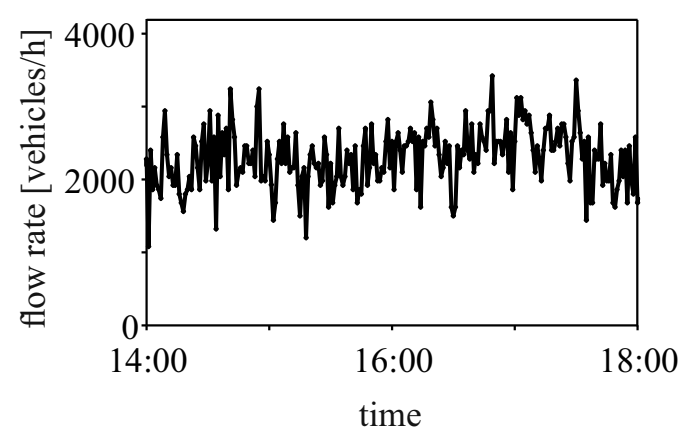

(b) “Südring I", April 12, 2013: flow rate

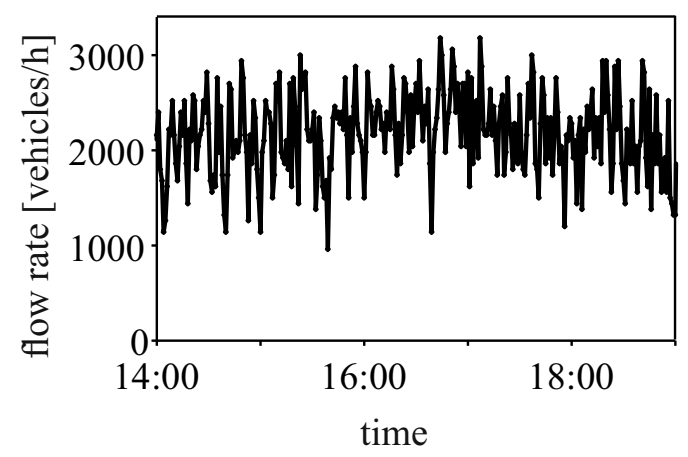

(d) "Südring II", Jan 16, 2013: flow rate

Figure 4 Typical city traffic detector data: average speed and total flow rate across or two-lane (a,b) or, respectively, three-lane (c,d) road measured by stationary detectors marked "DSI" (a,b) and "DSII" in Fig. 1(b) and 2.

earlier observations in different countries [35,36], can be observed by means of stationary road detectors (compare Fig. 3 and 4): At a small flow rate, vehicles move at free flow speed. After the flow rate has increased considerably, a strong and abrupt drop in speed is observed.

The stationary road detectors determine the averaged velocity and flow rate per minute based on a data stream of an optical camera. The accuracy of the processed data is influenced by weather conditions like precipitation, illumination conditions, overlaps caused by large vehicles as well as the applied object recognition and tracking algorithms (compare [37] for a discussion of errors).

In all examples from Fig. 3 and 4, undersaturated traffic and oversaturated traffic can be distinguished by the mean vehicle speed. This is also the case for the example from Völklinger Straße, even though the measured speed in undersaturated traffic is considerably below the speed limit for the whole day (see Fig. 3(a,b)). The relatively low speed in undersaturated city traffic can be explained with the detector position at the upstream end of Völklinger Straße: When passing the detector, the vehicles have not yet fully accelerated after having turned into this road.

A typical observation is that the drop in speed is considerably stronger than the drop in the flow rate (compare Fig. 3(c,d), 7:48-9:15). In the examples shown in Fig. 4(a,b), 
14:46-17:30, and Fig. 4(c,d), 15:32-17:08, the flow rate after the drop in speed is on average as high as before the drop in speed. Due to the fact that the drop in speed is considerably stronger than the drop in the flow rate, we refer to this common case of traffic breakdown as "speed breakdown". In the case of speed breakdown SPs, MQs, and mixtures between SPs and MQs are observed in oversaturated city traffic.

In contrast to the case of speed breakdown discussed above, another empirical example of traffic breakdown is found in Fig. 3(a,b) where both the speed and the flow rate drop considerably (9:47-9:54). We call this case "speed and flow rate breakdown". Speed and flow rate breakdown results from heavy bottlenecks, e.g. roadworks or accidents. A mega-queue is observed after speed and flow rate breakdown, which has the same structure as a mega-jam in highway traffic [38]. No synchronized flow is observed within a mega-queue. For this reason, we only consider the case of speed breakdown in this article.

\subsection{Synchronised flow patterns}

Empirical examples of synchronised flow patterns are shown in Fig. 5-7. Each subfigure is a speed-time plot of a single vehicle. The depicted single-vehicle speeds derived from anonymised real-field GNSS data exhibit vehicle motion at synchronised flow speed (marked "SP" in the figures), which is considerably lower than free flow speed. However, the vehicles stop only once at the traffic signal; there are no additional stops and thus no traffic flow interruption within the SPs. 


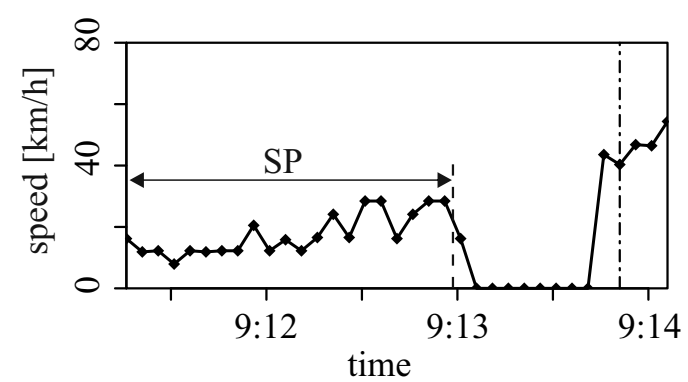

(a) Völklinger Straße, Nov 7, 2011

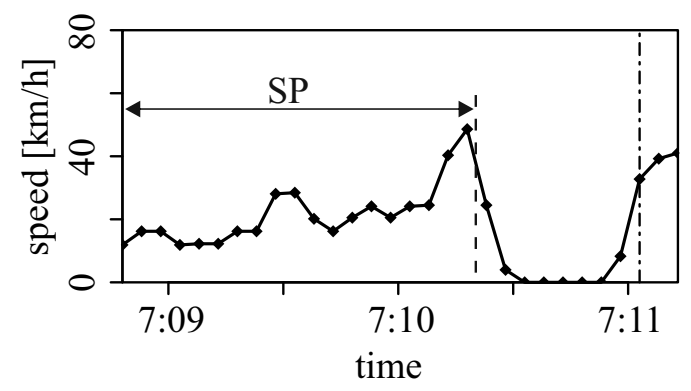

(c) Völklinger Straße, Nov 21, 2011

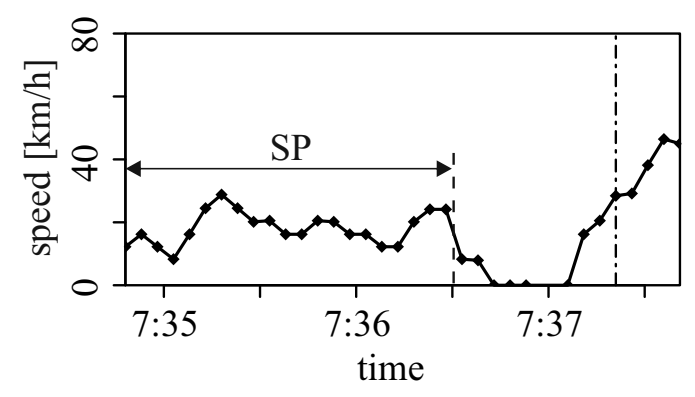

(e) Völklinger Straße, Dec 21, 2011

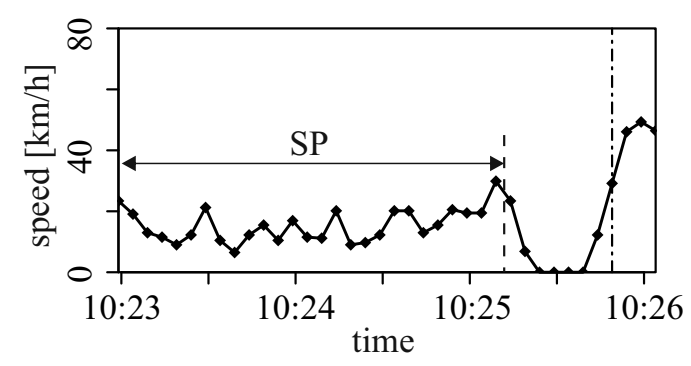

(g) Völklinger Straße, May 17, 2013

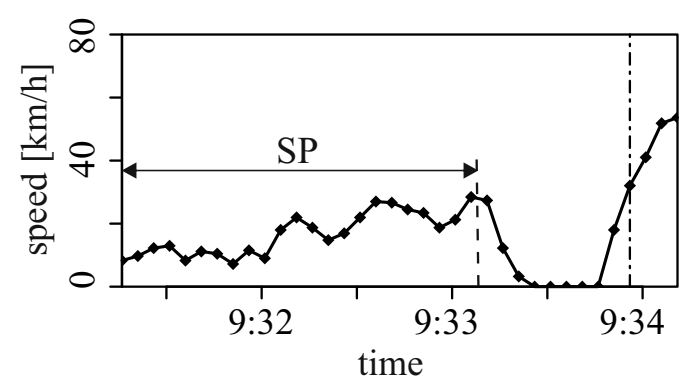

(b) Völklinger Straße, Nov 9, 2011

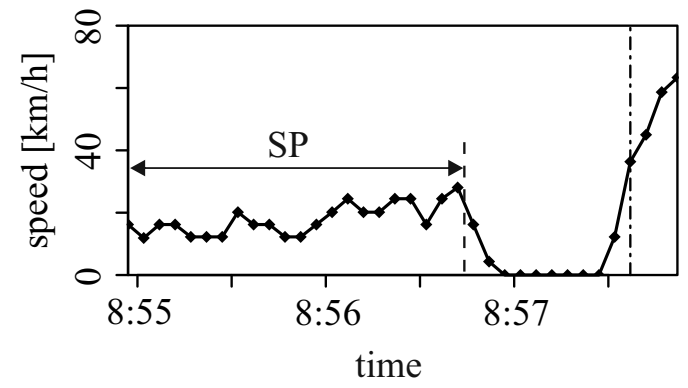

(d) Völklinger Straße, Dec 1, 2011

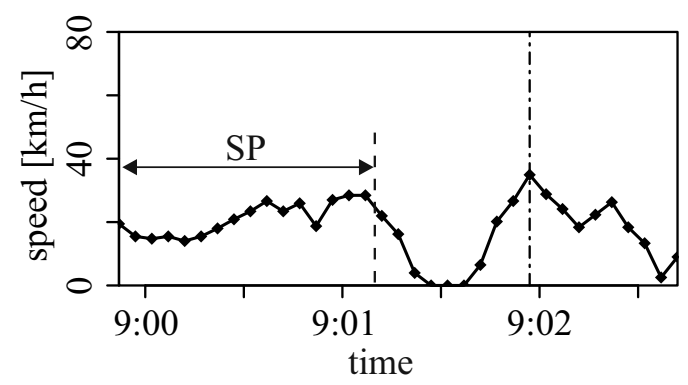

(f) Völklinger Straße, April 10, 2013

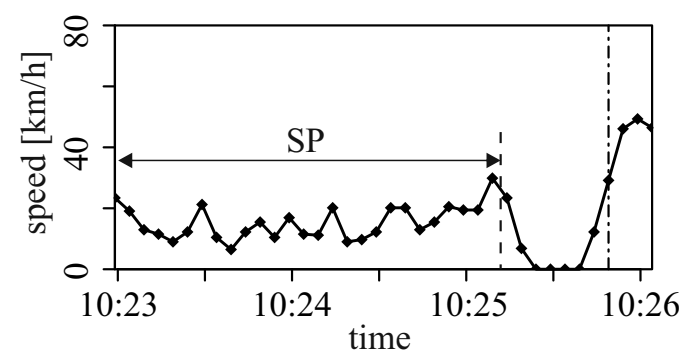

(h) Völklinger Straße, July 22, 2013

Figure 5 Empirical synchronised flow patterns (SPs): single-vehicle speed-time plots from anonymised GNSS probe data measured by navigation devices in vehicles. Dash-dotted lines indicate the time instant of the first measurement after the vehicle has passed the traffic signal and thus left the road section under consideration. Subfigure captions refer to road section and date of measurement. 


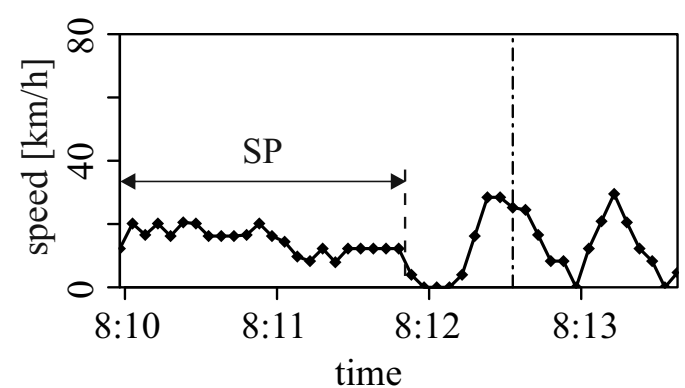

(a) Völklinger Straße, Sep 25, 2013

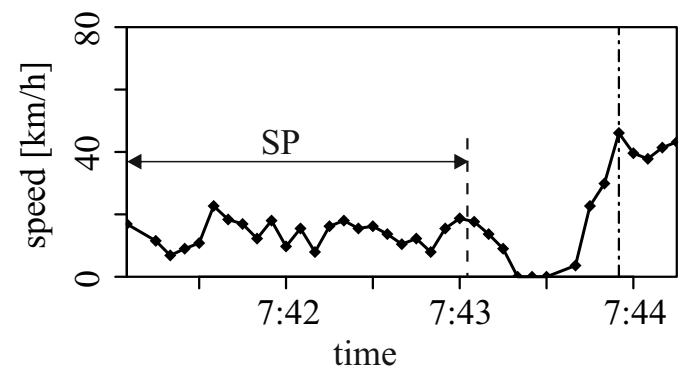

(c) Völklinger Straße, Oct 18, 2013

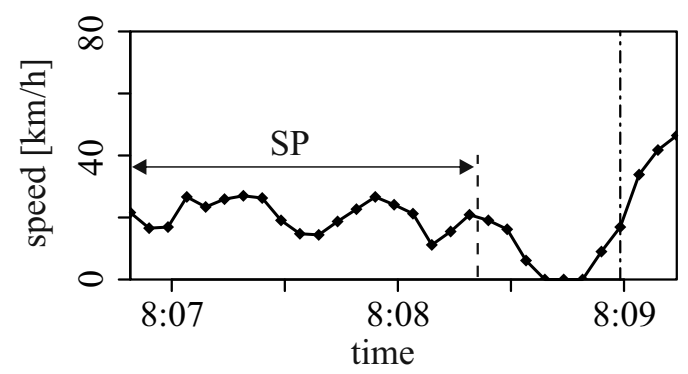

(e) "Südring I", April 10, 2013

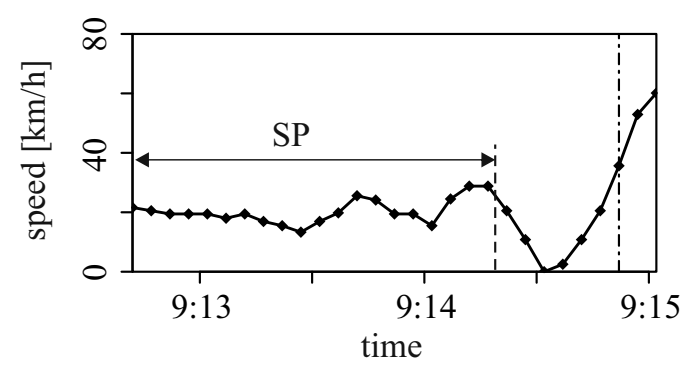

(g) “Südring I", July 1, 2013

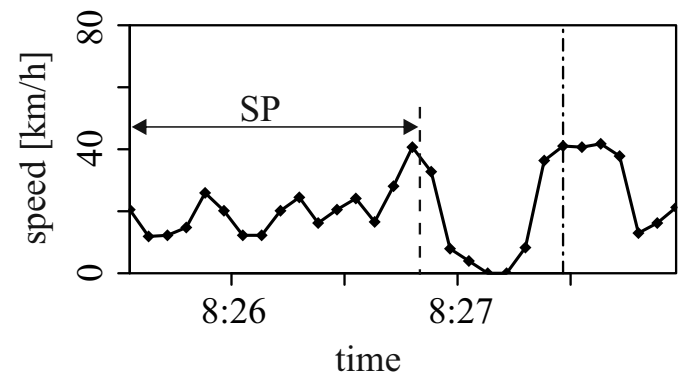

(b) Völklinger Straße, Sep 25, 2013

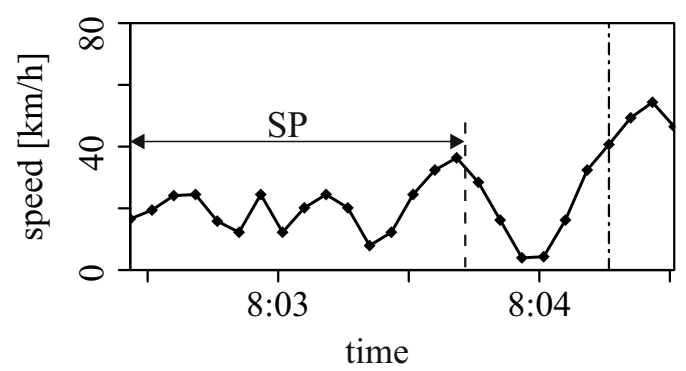

(d) Völklinger Straße, Jan 16, 2014

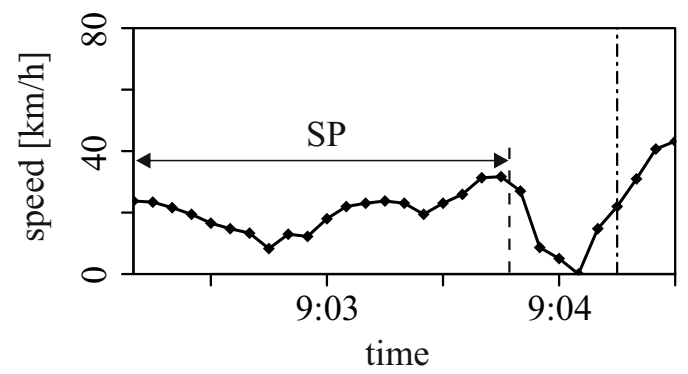

(f) "Südring I", April 29, 2013

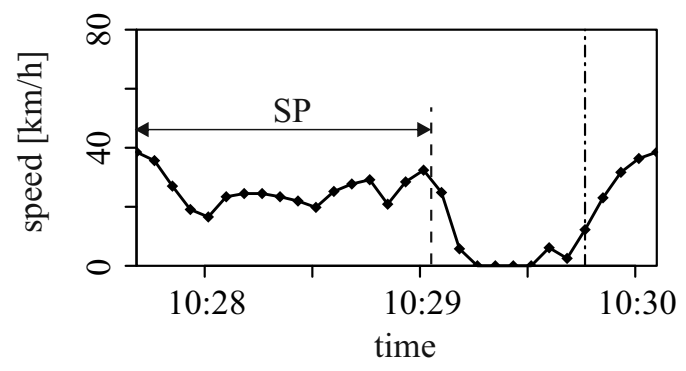

(h) "Südring I", Oct 16, 2013

Figure 6 Empirical synchronised flow patterns (SPs): single-vehicle speed-time plots from anonymised GNSS probe data measured by navigation devices in vehicles. Dash-dotted lines indicate the time instant of the first measurement after the vehicle has passed the traffic signal and thus left the road section under consideration. Subfigure captions refer to road section and date of measurement. 


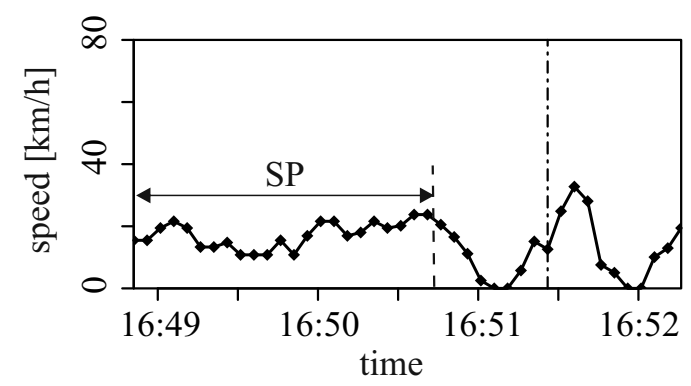

(a) "Südring I", Nov 7, 2013

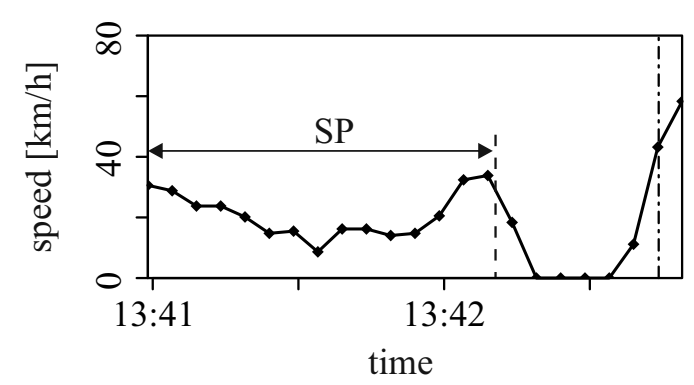

(c) “Südring II", June 13, 2013

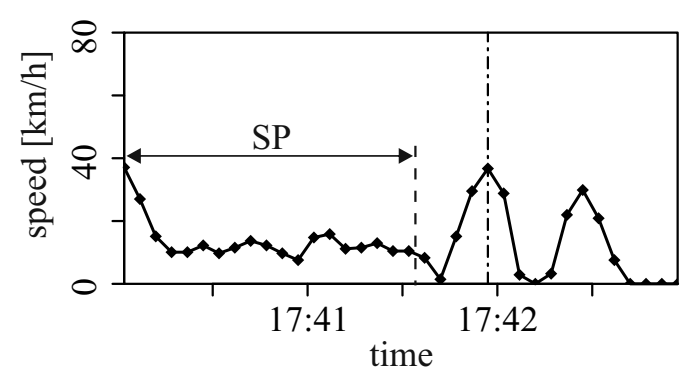

(b) "Südring II", April 12, 2013

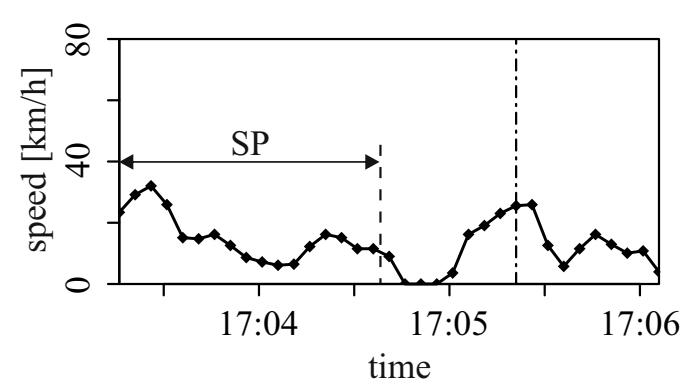

(d) “Südring II", Jan 16, 2013

Figure 7 Empirical synchronised flow patterns (SPs): single-vehicle speed-time plots from anonymised GNSS probe data measured by navigation devices in vehicles. Dash-dotted lines indicate the time instant of the first measurement after the vehicle has passed the traffic signal and thus left the road section under consideration. Subfigure captions refer to road section and date of measurement.

\subsection{Classical sequences of moving queues}

Empirical single-vehicle speeds associated with regular sequences of moving queues observed on the considered road sections are shown in Fig. 8. In contrast to the SPs discussed in the previous section, traffic flow is interrupted as the vehicles regularly stop several times in queues. When leaving a queue, a vehicle accelerates from speed zero, moves forward and, after some seconds, decelerates again to stop in the next moving queue.

\section{Energy efficiency of vehicles}

There are considerable qualitative differences between empirical SPs and MQs, as discussed in Sec. 2: While there can be similar mean vehicle speeds in SPs and MQs, these traffic patterns differ considerably with regard to the acceleration behaviour of the vehicles. As is well known, the fuel consumption (or, respectively, the electrical energy used by an electrical vehicle) depends on both speed and acceleration. Therefore, the occurrence of SPs in oversaturated city traffic obviously exhibits an impact on the energy efficiency of vehicles. 


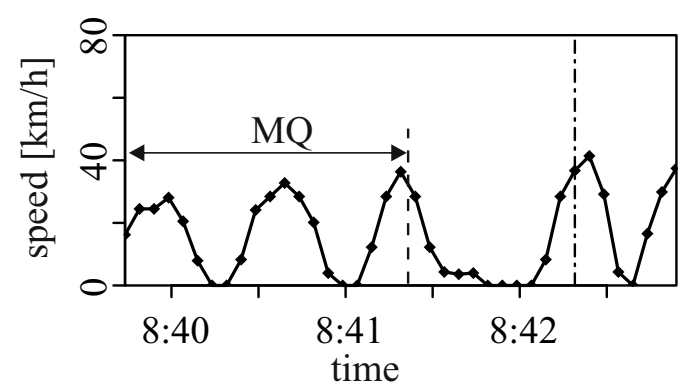

(a) Völklinger Straße, July 1, 2013

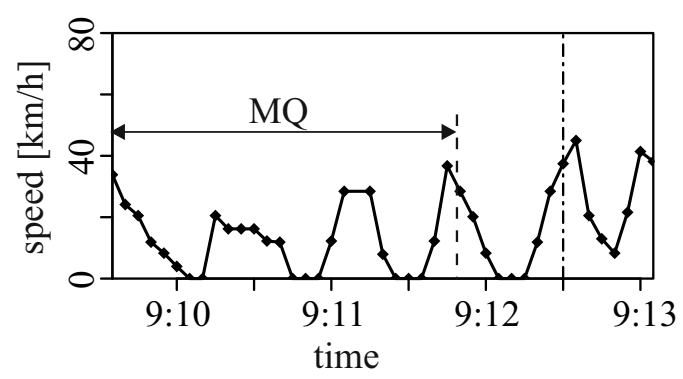

(c) Völklinger Straße, Nov 18, 2013

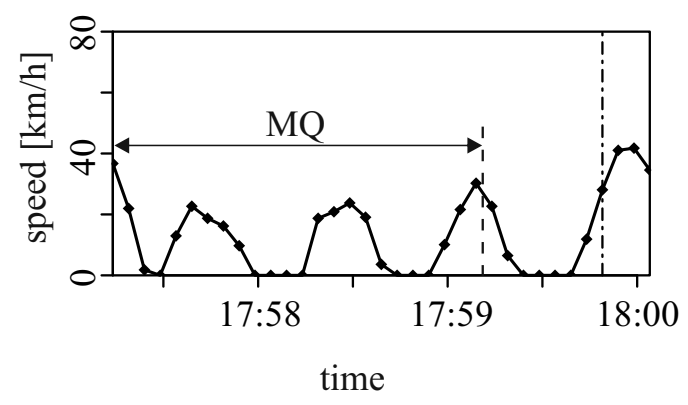

(e) "Südring II", April 10, 2013

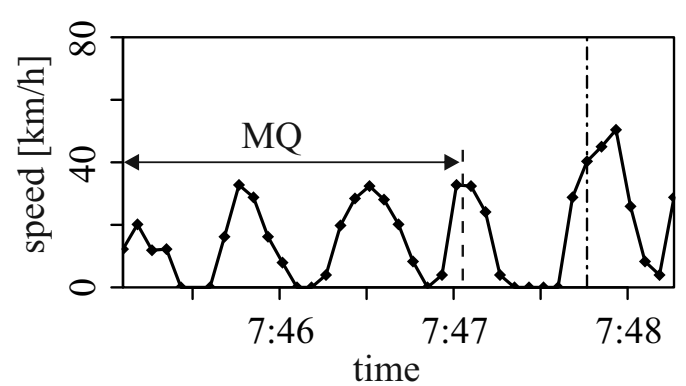

(b) Völklinger Straße, Sep 25, 2013

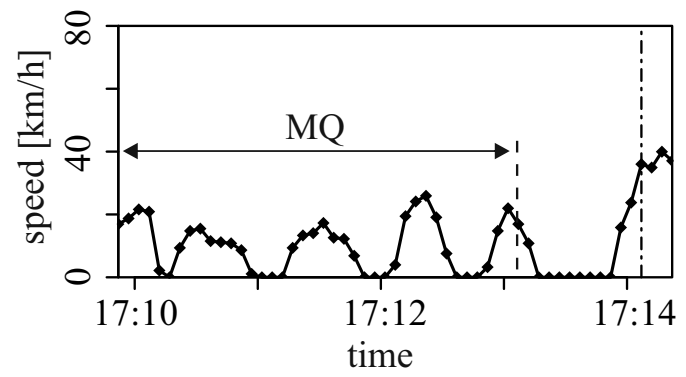

(d) "Südring I", April 17, 2013

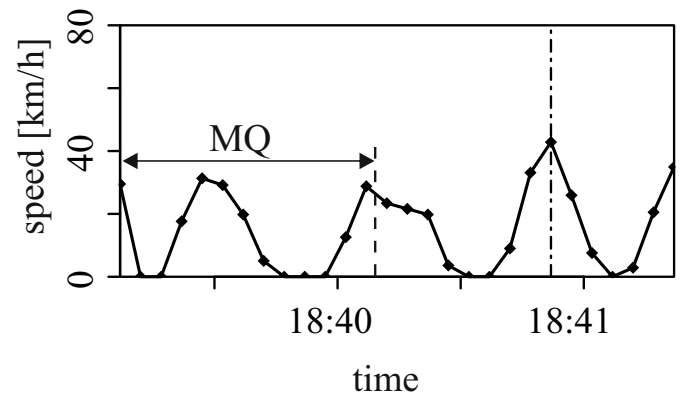

(f) "Südring II", April 10, 2013

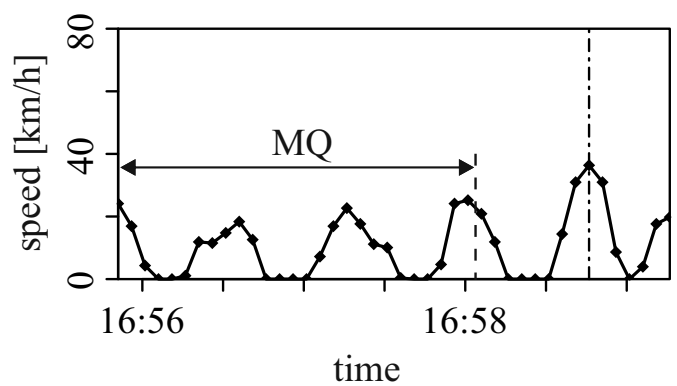

(g) "Südring II", April 15, 2013

Figure 8 Empirical sequences of moving queues (MQs): single-vehicle speed-time plots from anonymised GNSS probe data measured by navigation devices in vehicles. Dash-dotted lines indicate the time instant of the first measurement after the vehicle has passed the traffic signal and thus left the road section under consideration. Subfigure captions refer to road section and date of measurement. 


\subsection{Cumulated acceleration}

To assess the impact of SPs in oversaturated city traffic on the energy efficiency based on GNSS data, one needs to consider what information on the vehicle acceleration can be extracted from the data. If the temporal resolution of the data is sufficient, one can consider the reconstruction of acceleration profiles using smoothing methods to reduce the error resulting from GNSS measurements [39]. However, taking into account that relevant acceleration procedures typically occur within a time scale of $1 \mathrm{~s}$, acceleration profiles cannot reliably be calculated from GNSS data if the interval between position measurements is $5 \mathrm{~s}$. For this reason, we take the following approach.

To assess the dependency of traffic patterns on energy efficiency, we use a parameter that can feasibly be calculated on the basis of GNSS data from navigation devices and that correlates with the energy efficiency of vehicles. In particular, taking into account the aforementioned dependency of energy efficiency on acceleration, we choose a macroscopic parameter which sums up how often and how strongly a vehicle accelerates along a road section. The best information on these acceleration processes available from GNSS data is the speed differences $v_{n+1}-v_{n}$ between two successive GNSS measurements in a vehicle travelling on a road. The cumulated vehicle acceleration per road length (or "cumulated acceleration" for short), which has been introduced by Kerner for a reliable on-line assessment of fuel consumption in vehicles, is a sum of positive speed differences between GNSS measurements [40].

The cumulated acceleration $A$ per length, which refers to a vehicle travelling on a road section of length $L$, is defined by the formula [40]

$$
A=L^{-1} \sum_{n=1}^{N-1}\left(v_{n+1}-v_{n}\right) \Theta\left[v_{n+1}-v_{n}-\Delta v\right],
$$

where $\Theta[x]$ is the Heaviside function, and $\Delta v \geq 0$ is used to reduce the effect of the error resulting from speed calculations from GNSS data. For GNSS data with $\Delta t=5 \mathrm{~s}$ between two successive GNSS measurements, we use $\Delta v=0.5 \mathrm{~km} / \mathrm{h}$. The definition of $A$ is based on the assumption that the vehicle acceleration $a_{n}$ during time interval $t_{n+1}-t_{n}$ between GNSS measurements (length $\Delta t$ ) is time-independent,

$$
a_{n}=\frac{v_{n+1}-v_{n}}{\Delta t}
$$

The cumulated vehicle acceleration can be applied for any link of a traffic network, independent of the length of the link. Furthermore, it can be applied for any time interval $\Delta t$ between successive GNSS measurements. It should be noted that the cumulated vehicle acceleration is dependent on $\Delta t$. Obviously, the larger $\Delta t$, the more information on the acceleration behaviour of the vehicle is lost. However, it is assumed that only values of $A$ for different vehicle trajectories with the same $\Delta t$ are compared. For this reason, $\Delta t$ does not explicitly appear in Eq. 3. As a consequence of this and of the division by $L$ in Eq. 3, the dimension of $A$ is not acceleration, but reciprocal time. We choose $\mathrm{h}^{-1}$ as unit.

In Fig. 9, idealised speed profiles along a road of length $1 \mathrm{~km}$ are shown. These artificial examples are not intended to reflect real traffic features, but give an understanding for the order of magnitude of the cumulated acceleration in certain situations: If the vehicle 


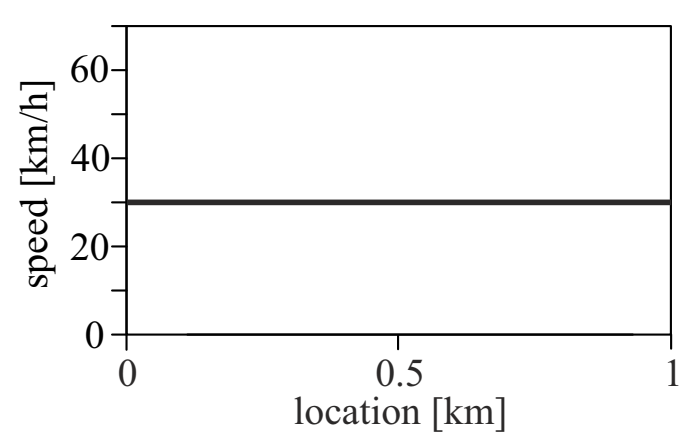

(a) $A=0 \mathrm{~h}^{-1}$

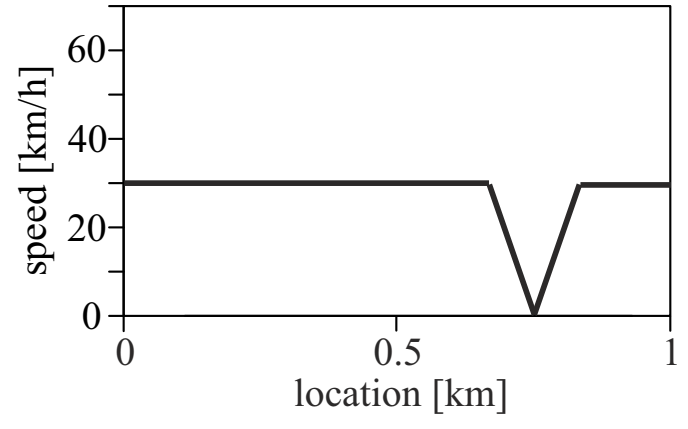

(b) $A=30 \mathrm{~h}^{-1}$

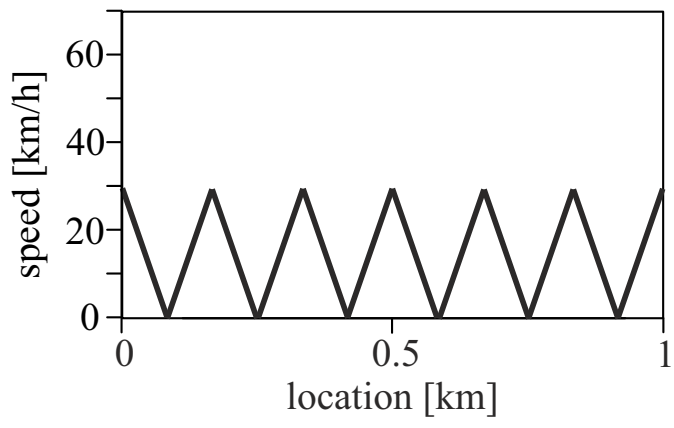

(c) $A=180 \mathrm{~h}^{-1}$

Figure 9 Hypothetical vehicle speeds on a road of length $L=1 \mathrm{~km}$ with different values of the cumulated vehicle acceleration $A$ [34]

acceleration is time-independent and equal to zero, then the cumulated acceleration $A$ is also zero (Fig. 9(a)). If there is only one acceleration procedure from $0 \mathrm{~km} / \mathrm{h}$ to $30 \mathrm{~km} / \mathrm{h}$, then $A=30 \mathrm{~h}^{-1}$ (Fig. 9(b)). If there are six acceleration procedures from $0 \mathrm{~km} / \mathrm{h}$ to 30 $\mathrm{km} / \mathrm{h}$, then $A=180 \mathrm{~h}^{-1}$ (Fig. 9(c)).

An alternative quantity for the assessment of the energy consumption of vehicles is the positive kinetic energy per unit distance (PKE), where the differences of the squared speeds $v_{n+1}^{2}-v_{n}^{2}$ are summed up instead of the speed differences [41]. We use the cumulated acceleration for the following reason.

We aim to assess the total energy used by a vehicle while driving. Apart from the kinetic energy, the total energy depends on other parameters related to, e.g., drag, road grade, electrical loads such as radio, and the energy conversion efficiency of the engine. As will be discussed in the next section, our energy calculations are based on empirical microscopic energy matrices that express the total energy in terms of vehicle speed and vehicle acceleration. The cumulated acceleration expresses the dependency of the energy on the acceleration. Electrical vehicles do not only consume the energy stored in the battery while driving. The regenerative brake of an electrical vehicle allows energy recovery. To account for the energy recovery of an electrical vehicle, we define the cumulated deceleration $D$ analogously to Eq. 3 by the formula

$$
D=L^{-1} \sum_{n=1}^{N-1}\left(v_{n+1}-v_{n}\right) \Theta\left[-\left(v_{n+1}-v_{n}\right)-\Delta v\right]
$$


We will use the cumulated deceleration in Sec. 4 when discussing energy-efficient route guidance for conventional and electrical vehicles.

\subsection{Cumulated acceleration of empirical SPs}

For the examples of empirical SPs and MQs discussed in Sec. 2, the dependency of the cumulated acceleration $A$ on the mean speed $V$ along the vehicle trajectory on the considered road sections is shown in Fig. 10(a). For the empirical MQs, the mean speeds are between $8 \mathrm{~km} / \mathrm{h}$ and $14 \mathrm{~km} / \mathrm{h}$. For the empirical SPs there are mean speeds between 12 $\mathrm{km} / \mathrm{h}$ and $20 \mathrm{~km} / \mathrm{h}$.

As can be seen in Fig. 10(a), the cumulated acceleration is considerably greater for empirical MQs than for empirical SPs: There are values of $A$ between $170 \mathrm{~h}^{-1}$ and 220 $\mathrm{h}^{-1}$ for the empirical MQs. On the other hand, or the empirical SPs the values of the cumulated acceleration $A$ are between $50 \mathrm{~h}^{-1}$ and $160 \mathrm{~h}^{-1}$. There is no overlap between the ranges of $A$ for the empirical SPs and MQs.

In Fig. 10(b), the dependency of the cumulated acceleration $A$ on the mean speed $V$ is shown again for all examples of empirical MQs and SPs from Sec. 2 with mean speeds between $10 \mathrm{~km} / \mathrm{h}$ and $15 \mathrm{~km} / \mathrm{h}$. This is the range in which the mean speeds along vehicle trajectories in SPs and MQs overlap. It can be seen that the cumulated acceleration is considerably greater for MQs than for SPs even when the mean vehicle speeds along vehicle trajectories are similar. This result is underlined by the average cumulated acceleration, which is $108 \mathrm{~h}^{-1}$ for the SPs and $194 \mathrm{~h}^{-1}$ for the MQs (compare the horizontal lines in Fig. 10(b)).

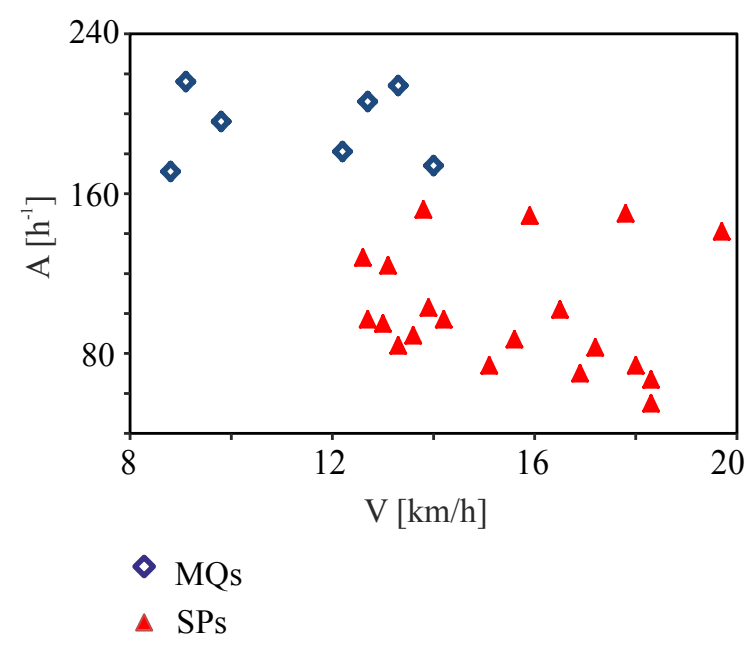

(a) All examples shown in Fig. 5-8

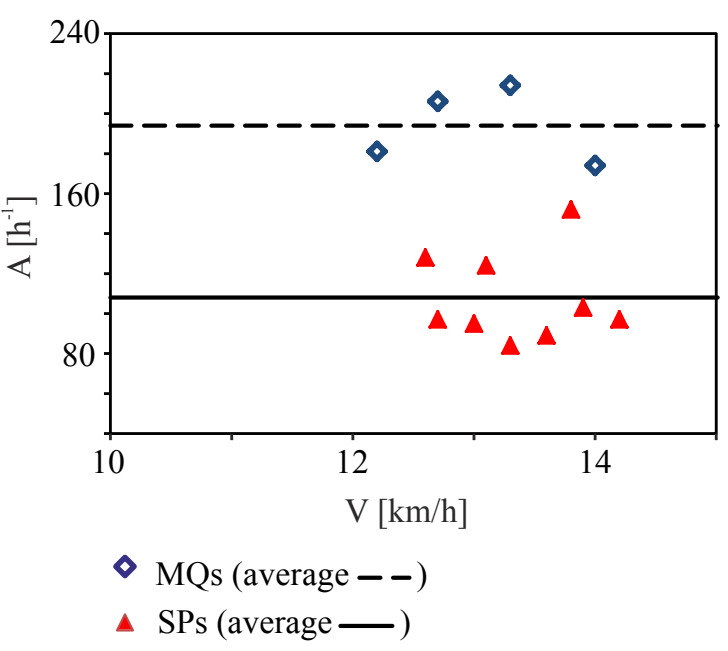

(b) Examples shown in Fig. 5-8 with mean speeds along the vehicle trajectory between $10 \mathrm{~km} / \mathrm{h}$ and $15 \mathrm{~km} / \mathrm{h}$

Figure 10 Dependency of the cumulated vehicle acceleration $A$ on the mean speed $V$ for the empirical SPs and MQs discussed in Sec. 2 


\subsection{Empirical microscopic energy matrices}

For energy efficiency calculations, we use empirical microscopic consumption matrices. These matrices are based on empirical CAN (Controller Area Network) bus data of speed, acceleration and fuel consumption or, respectively, electrical energy recorded from the following vehicles: a conventional medium-sized vehicle with a combustion engine [4245] and a Smart electric drive. These vehicles were driven during field trials in real traffic [42]. Neither data from test bench measurements nor consumption models (compare [20]) were used. In the electric vehicle, no acceleration signal was recorded in the field trial. The acceleration values used here were therefore derived from the speed.

The empirical microscopic matrices were aggregated by grouping energy values into matrix elements according to their associated speed and acceleration values. For each matrix element, the energy median was then calculated. Visualisations of the resulting energy matrices are shown in Fig. 11, where normalised energy scales are used: For the fuel consumption, which is a measure of the energy consumption of conventional vehicles, the normalised values are between 0 and 1 (Fig. 11(a)). For the electrical vehicle, due to energy regeneration associated with braking, several energy values associated with negative acceleration are negative Fig. 11(b).

In the case of the conventional vehicle (Fig. 11(a)), field trial data measured over 90 hours on 20 different days were used. The vehicle was driven by different drivers on different roads, both freeways and urban roads. More than 10 million data points were recorded and aggregated. The aggregation intervals are $2 \mathrm{~km} / \mathrm{h}$ and $0.1 \mathrm{~m} / \mathrm{s}^{2}$, respectively.

The empirical microscopic matrix for an electrical vehicle was aggregated on the basis of about 146,000 data points. The resolution of the speed values is $1 \mathrm{~km} / \mathrm{h}$. The aggregation intervals are $2 \mathrm{~km} / \mathrm{h}$ (as in the case of the conventional vehicle) and $0.278 \mathrm{~m} / \mathrm{s}^{2}$ (resulting from the measurement accuracy of the speed values from which the acceleration was derived).

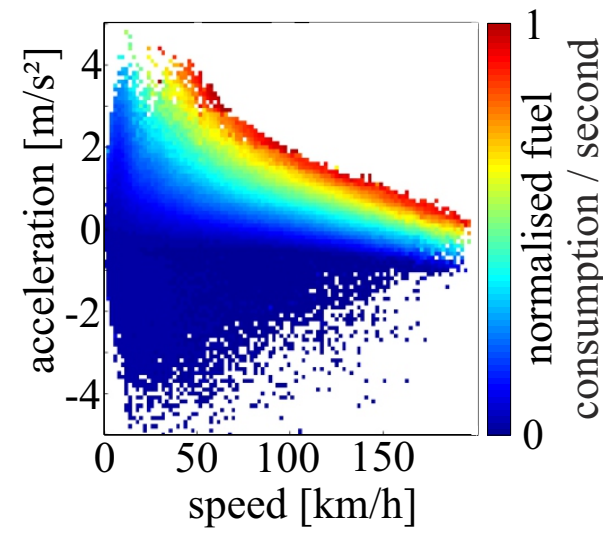

(a) Consumption matrix for a conventional vehicle [42]

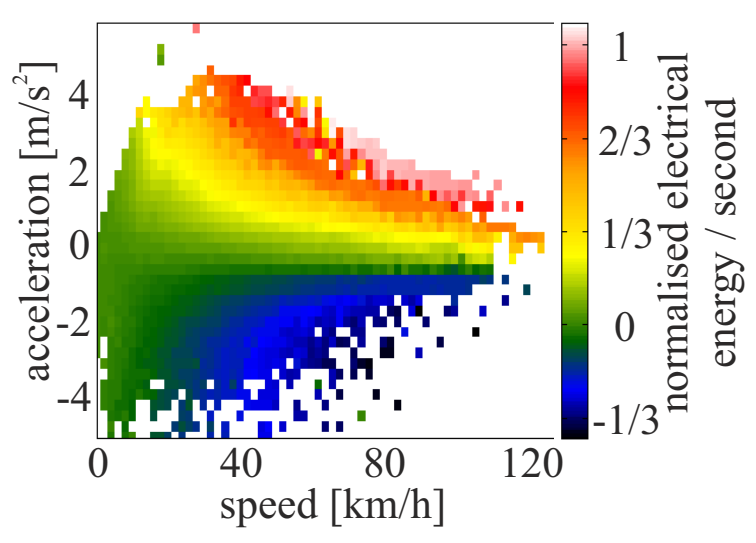

(b) Energy matrix for an electrical vehicle

Figure 11 Empirical microscopic energy matrices 


\subsection{Dependency of relative consumption and electrical energy on time-independent speed}

For consumption calculations with the empirical microscopic consumption matrix shown in Fig. 11(a), second-by second speed and acceleration values $v_{1}, \ldots, v_{N}$ and $a_{1}, \ldots, a_{N}$ along a vehicle trajectory are needed as input [42]. For each time step $n$, the instantaneous consumption $c_{n}$ associated with the pair $\left(v_{n}, a_{n}\right)$ of speed and acceleration values is looked up in the microscopic matrix. The total consumption $C_{k, j}$ along vehicle trajectory $k$ on road link $j$ is then obtained by summing up the instantaneous consumption values $c_{n}$,

$$
C_{k, j}=\sum_{n=1}^{N} c_{n} .
$$

The relative fuel consumption $C_{\mathrm{rel} ; k, j}$ of vehicle trajectory $k$ on road link $j$ can then be written as

$$
C_{k, j}^{\mathrm{rel}}=\frac{C_{k, j}}{C_{\mathrm{I}, j}},
$$

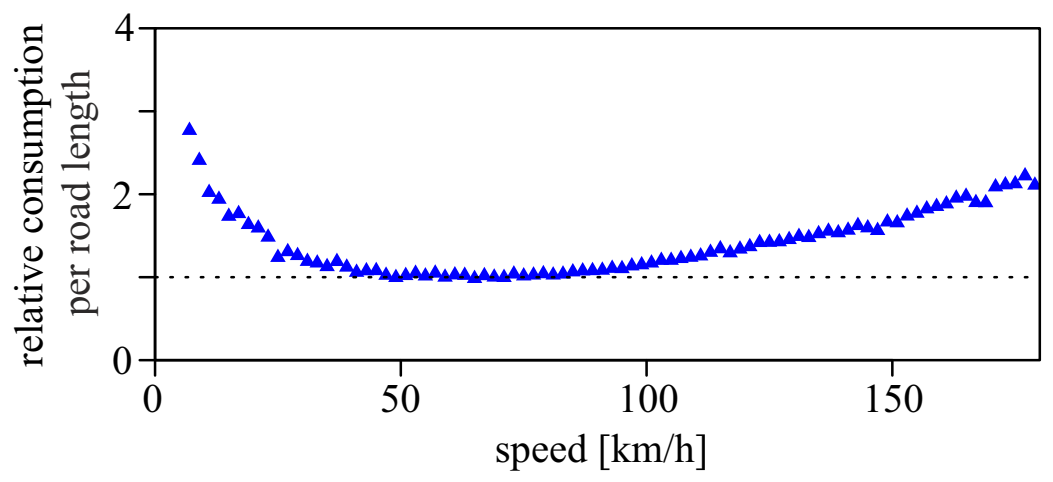

(a) Conventional vehicle [42]

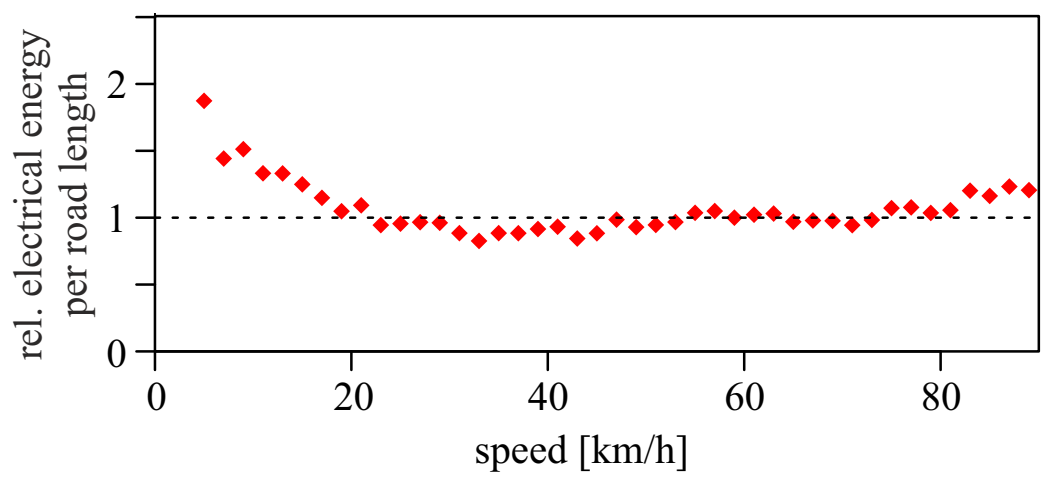

(b) Electrical vehicle

Figure 12 Relative fuel consumption (a) or electrical energy (b) of drives on a road section with timeindependent speed. Calculations based on the empirical microscopic energy matrices qualitatively reproduce well-known results from literature [46]. 
where $C_{\mathrm{I}, j}$ denotes the fuel consumption of a hypothetical trajectory with time-independent speed $60 \mathrm{~km} / \mathrm{h}$ on a road of the same length as link $j$. Relative consumption values are sufficient in view of our aim to assess the impact of certain congested traffic patterns on consumption; absolute values are not needed for this purpose. The unit $C_{\mathrm{I}, j}$ was chosen to express "perfect" city traffic conditions of an idealized green wave. The relative fuel consumption is dimensionless. The relative electrical energy is calculated analogously to the relative fuel consumption.

As a proof of plausibility of the empirical microscopic consumption, we apply the matrix to drives of vehicles on a road stretch of fixed length with different time-independent speeds. The resulting dependency of fuel consumption on time-independent speed is shown in Fig. 12(a). There is a wide consumption minimum between $40 \mathrm{~km} / \mathrm{h}$ and 80 $\mathrm{km} / \mathrm{h}$. For speeds lower than $40 \mathrm{~km} / \mathrm{h}$, the consumption increases with decreasing speed. These findings are in accordance with well-known results from literature (e.g. [46]).

For the electrical vehicle, the dependency of the electrical energy used while driving on the time-independent speed is shown in Fig. 12(b). As in the case of the conventional vehicle, there is a wide minimum, which in this case stretches from about $20 \mathrm{~km} / \mathrm{h}$ to 80 $\mathrm{km} / \mathrm{h}$. Again, there is increase in energy with decreasing speed in the range on the left of the wide energy minimum. However, due to measurement inaccuracy, there is great scattering of the energy values.

\subsection{Cumulated acceleration and energy efficiency of vehicles}

To examine the connection between cumulated acceleration and energy efficiency of vehicles, we combine the empirical microscopic energy matrices discussed in Sec. 3.3 with vehicle trajectories from a traffic flow simulation. Second-by-second speed and acceleration values $v_{1}, \ldots, v_{N}$ and $a_{1}, \ldots, a_{N}$ are used as input for the empirical microscopic energy matrices. Traffic flow simulations are used for the following reasons. First, a traffic flow simulation can provide a complete set of second-by-second speed and acceleration values for a simulation run. Second, if enough simulation runs are made, an amount of simulated trajectories which is sufficient for a statistical assessment of the dependency of the energy efficiency on the traffic situation.

For an examination of the impact of SPs on the energy efficiency of vehicles, it is required that the traffic flow model used for the simulations is able to reproduce SPs. To guarantee this, simulations were used that are based on a stochastic Kerner-Klenov model [47-51] which is in the framework of three-phase traffic theory. In accordance with the empirical observations of oversaturated city traffic, this model can reproduce both SPs and MQs [32].

We used speed and acceleration time series of more than 400,000 simulated vehicle trajectories provided by Hermanns that reproduce various scenarios of city traffic [52]. All simulated speed and acceleration time series were fed to the empirical microscopic consumption matrix (Fig. 11(a)). For the rest of this section, we focus on conventional vehicles. We will return to electrical vehicles in Sec. 4.

To examine the relationship between SPs and energy efficiency of vehicles, we chose all simulated trajectories with mean speeds along the trajectory between $10 \mathrm{~km} / \mathrm{h}$ and 15 


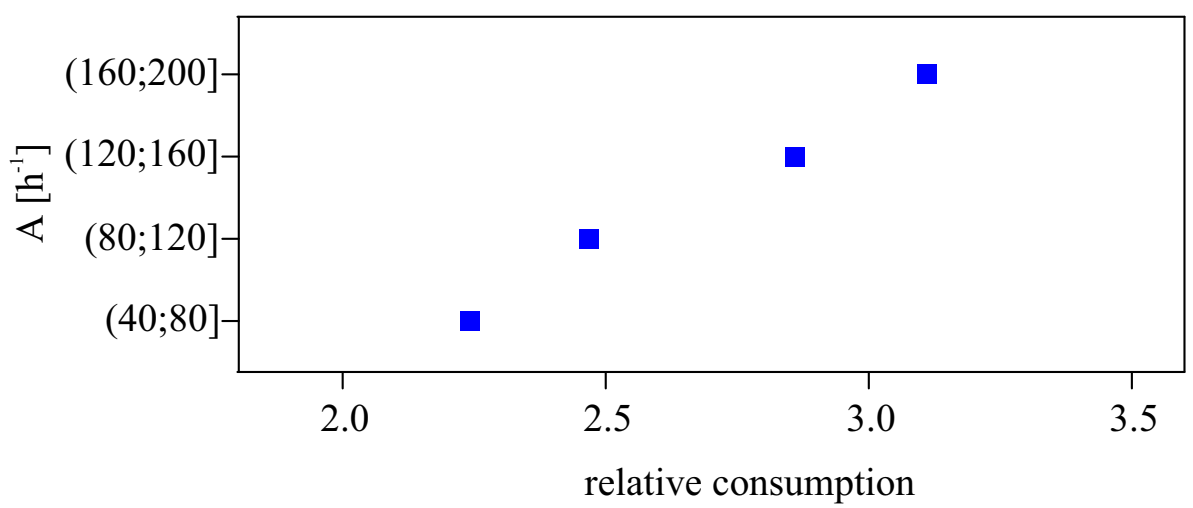

Figure 13 Mean dependency of the relative fuel consumption on the cumulated acceleration $A$ for mean speeds between $10 \mathrm{~km} / \mathrm{h}$ and $15 \mathrm{~km} / \mathrm{h} \mathrm{[34]}$

$\mathrm{km} / \mathrm{h}$, the range in which there are both empirical SPs and MQs (compare Fig. 10(b)). According to the cumulated acceleration, these simulated trajectories were grouped into classes of width $40 \mathrm{~h}^{-1}$. Average fuel consumption values were calculated for all classes with at least 50 representatives.

The resulting dependency of consumption on the energy efficiency of vehicles is shown in Fig. 13. Clearly, the fuel consumption increases with increasing cumulated acceleration.

To understand the relationship between fuel consumption and SPs, we return to the results on the cumulated acceleration associated with empirical SPs and MQs studied in section Sec. 3.2. We regard the cumulated acceleration of vehicle trajectories empirical SPs and MQs with means speeds between $10 \mathrm{~km} / \mathrm{h}$ and $15 \mathrm{~km} / \mathrm{h}$ (Fig. 10(b)), and connect it with the dependency of fuel consumption on the cumulated acceleration (Fig. 13). The average cumulated acceleration of SPs, $108 \mathrm{~h}^{-1}$, is associated with an average relative fuel consumption 2.5. On the other hand, the average cumulated acceleration for MQs (194 $\mathrm{h}^{-1}$ ) is associated with an average relative fuel consumption 3.1. As a consequence, fuel consumption in oversaturated city traffic can be considerably reduced if the oversaturated city traffic consists only of SPs rather than consisting of both SPs and MQs [34].

\section{Applicability to on-line energy-efficient route guidance}

In several studies, the impact of traffic congestion on the fuel consumption and pollutant emission of conventional vehicles has been examined, e.g. [53-56]. Information on the amount of consumption and emissions associated with the links of a traffic network can be used in applications of energy-efficient route guidance, also called "eco-routing". In some works on eco-routing, consumption or emissions are not calculated for individual vehicle trajectories. Instead, road sections are classified according to macroscopic criteria. E.g., in [55], the level of service (LOS) of a road is mapped to consumption and emissions. A model for the energy efficiency of electrical vehicles and an algorithm for energy efficientrouting of electrical vehicles are presented in [57]. 


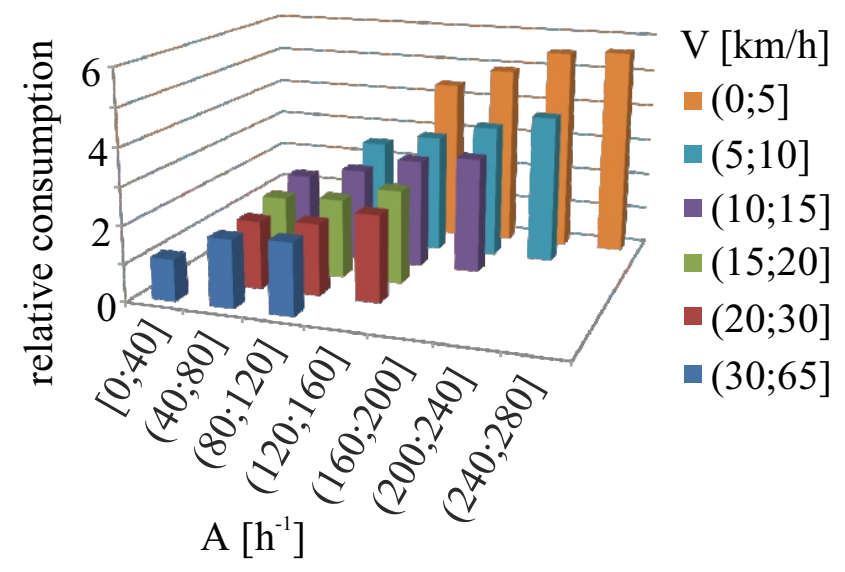

Figure 14 Macroscopic consumption matrix $M_{C}$ for a conventional vehicle with a combustion engine [34]

In this section, we present macroscopic energy matrices that express the average consumption of a road link as a function of mean speed, cumulated acceleration and, in the case of electrical vehicles, cumulated deceleration. We sketch the applicability of these macroscopic energy matrices to on-line energy-efficient route guidance by means of simple examples.

\subsection{Macroscopic energy matrices}

In Sec. 3.5 we studied the dependency of fuel consumption on the cumulated acceleration. Our results were based on an empirical microscopic consumption matrix and simulated speed and acceleration profiles. We regarded the simulated vehicle trajectories with mean speeds between $10 \mathrm{~km} / \mathrm{h}$ and $15 \mathrm{~km} / \mathrm{h}$. In this section we use more than 400,000 simulated vehicle trajectories with mean speeds between $0 \mathrm{~km} / \mathrm{h}$ and $65 \mathrm{~km} / \mathrm{h}$ to calculate the fuel consumption of conventional vehicles and the energy balance of electrical vehicles and to derive macroscopic energy matrices based on these calculations.

Macroscopic consumption matrix for a conventional vehicle The simulated vehicle trajectories are classified according to their mean speed $V$ along the trajectory and their cumulated acceleration $A$. As in Sec. 3.5, the aggregation interval width for $A$ is $40 \mathrm{~h}^{-1}$. For the mean speed, there are aggregation intervals of different widths (in the unit $\mathrm{km} / \mathrm{h}$ ): $(0 ; 5],(5 ; 10],(10 ; 15],(15 ; 20],(20 ; 30],(30 ; 65]$. For all classes with at least 50 vehicle trajectories, the average consumption was calculated. The resulting macroscopic consumption matrix $M_{C}$ is illustrated in Fig. 14.

Macroscopic consumption matrix $M_{C}$ for a conventional vehicle expresses the following dependency between mean speed, cumulated acceleration and fuel consumption [34].

1. For mean speeds between $0 \mathrm{~km} / \mathrm{h}$ and $65 \mathrm{~km} / \mathrm{h}$, fuel consumption increases with decreasing mean speed.

2. Fuel consumption increases with increasing cumulated acceleration. 


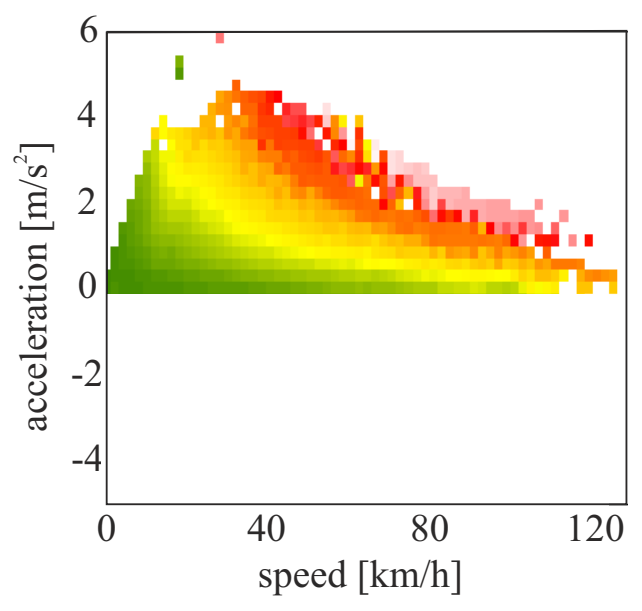

(a) $\mathrm{a} \geq 0$

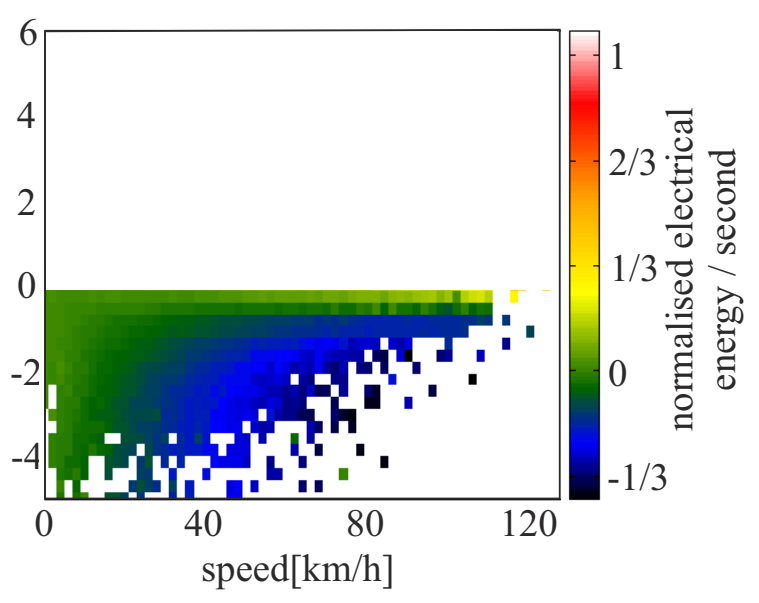

(b) a $<0$

Figure 15 Splitting the empirical microscopic energy matrix for an electrical vehicle (Fig. 11(b)) into two parts

Macroscopic energy matrices for an electrical vehicle For electrical vehicles we chose a modified approach to express the energy balance (the difference between the energy consumed and the energy regenerated while driving) as a function of mean speed $V$, cumulated acceleration $A$ and cumulated deceleration $D$. To this end, we split the empirical microscopic energy matrix (Fig. 11(b)) into two parts: one part that contains all combinations of speed and acceleration with non-negative acceleration values, and one part that contains all combinations with negative acceleration values (see Fig. 15).

Both partial microscopic energy matrices were applied to the same simulated vehicle trajectories as were used for the macroscopic matrix for a conventional vehicle. As a result, two macroscopic matrices were calculated that are shown in Fig. 16. Macroscopic energy matrix $M_{E 1}$ was calculated on the basis of the partial matrix containing non-negative acceleration values shown in Fig. 15(a). It expresses the mean dependency of electrical energy on mean speed $V$ and cumulated vehicle acceleration $A$. Macroscopic energy matrix $M_{E 2}$ was calculated on the basis of the partial matrix containing negative acceleration values shown in Fig. 15(b). It expresses the mean dependency of electrical energy on mean speed $V$ and cumulated deceleration $D$.

In $M_{E 2}$ (Fig. Fig. 16(b)) there are both negative entries where energy regeneration prevails $(15 \mathrm{~km} / \mathrm{h} \leq V \leq 65 \mathrm{~km} / \mathrm{h})$ and positive entries $(0 \mathrm{~km} / \mathrm{h} \leq V \leq 15 \mathrm{~km} / \mathrm{h})$ where energy consumption prevails. A comparison between $M_{E 1}$ and $M_{E 2}$ shows that for all mean speeds and possible combinations of $A$ and $D$, energy consumption considerably outweighs energy regeneration. $M_{E 1}$ is qualitatively similar to matrix $M_{C}$ for conventional vehicles.

The relative electrical energy balance $E^{\text {rel }}$ can be calculated with the formula

$$
E^{\mathrm{rel}}=E_{1}(V, A)+E_{2}(V, D)
$$

where $E_{1}(V, A)$ is read from matrix $M_{E 1}$ and $E_{2}(V, D)$ is read from matrix $M_{E 2}$. However, 


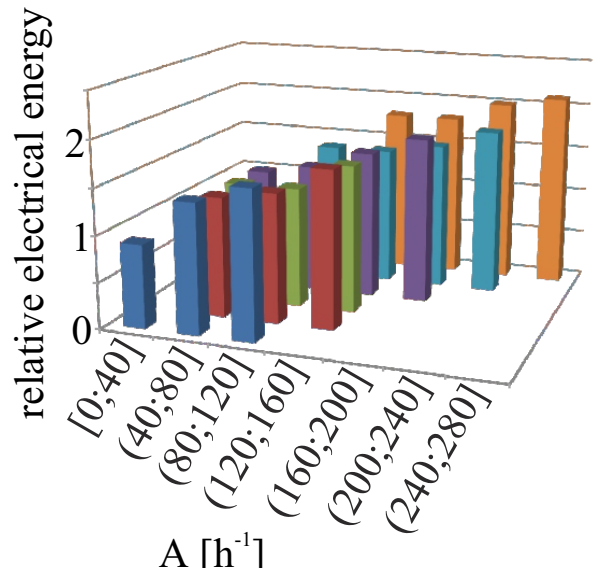

(a) The mean dependency of electrical energy on mean speed $V$ and cumulated vehicle acceleration $A$

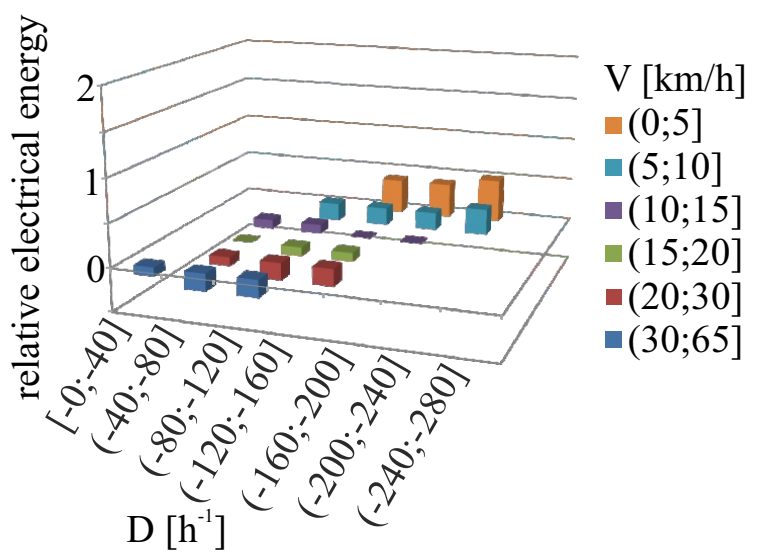

(b) The mean dependency of electrical energy on mean speed $V$ and cumulated vehicle deceleration $D$

Figure 16 Macroscopic energy matrices (a) $M_{E 1}$ and (b) $M_{E 2}$ for an electrical vehicle

for mean speeds between $0 \mathrm{~km} / \mathrm{h}$ and $20 \mathrm{~km} / \mathrm{h}$ that are associated with oversaturated city traffic, the relative electrical energy consumption according to $M_{E 1}$ and $M_{E 2}$ is considerably lower than the relative fuel consumption according to $M_{C}$. This means that according to matrices $M_{C}, M_{E 1}$ and $M_{E 2}$, the impact of oversaturated traffic on energy efficiency is stronger for a conventional vehicle than for an electrical vehicle. One has to keep in mind the different sizes of the vehicles that the energy data have been measured with.

\subsection{Application to road networks}

In the following, we illustrate by means of simple examples how the macroscopic matrices $M_{C}, M_{E 1}$ and $M_{E 2}$ can be applied to energy-efficient route guidance. We show that the most energy-efficient route between two points can be different from the fastest route. We also show that the most energy-efficient route for a conventional vehicle can be different from the most energy-efficient route for an electrical vehicle.

Comparison between fastest route and most energy-efficient route In a hypothetical road network sketched in Fig. 17, drivers can choose either route ACB or route ADB to get from point A to point B [34]. We assume that on both routes there are vehicles equipped with navigation devices that send GNSS data to a traffic server where the mean speed $V$, the cumulated acceleration $A$ and the cumulated deceleration $D$ are computed for each road section. We assume that the traffic is oversaturated on both roads and the mean speed is the same, $V_{A C B}=V_{A D B}$. Therefore, the shorter route ADB is the faster route. However, due to MQ occurrence on $\mathrm{ADB}$ and SP occurrence on $\mathrm{ACB}, A_{A D B}>A_{A C B}$. For simplicity, we assume that the absolute value of the cumulated deceleration $D$ is the same as $A$ for both routes. Possible values of $V_{j}, A_{j}, D_{j}$ and route length $L_{j}(j=\mathrm{ACB}, \mathrm{ADB})$ are given in Fig. 17. 


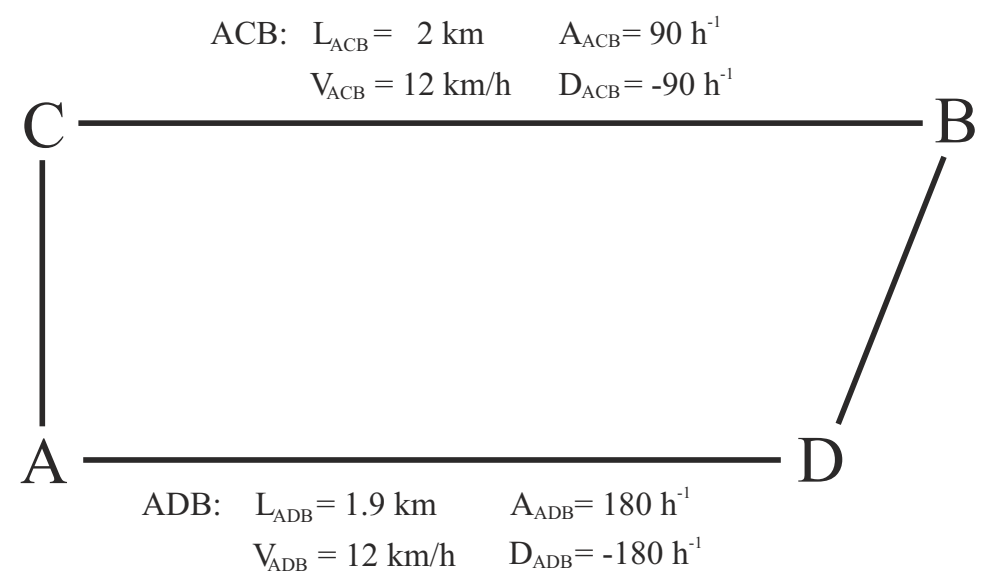

Figure 17 Schematic sketch of a subset of a hypothetical urban road network with two alternative routes ACB and ADB from point A to point B [34]

\begin{tabular}{lll}
\hline route $j$ & $\mathrm{ACB}$ & $\mathrm{ADB}$ \\
\hline$T_{j}$ & $600 \mathrm{~s}$ & $570 \mathrm{~s}$ \\
$C_{j}^{\text {rel }}$ & 2.5 & 3.1 \\
$C_{j}$ & 5 & 5.89 \\
$E_{j}^{\text {rel }}$ & 1.5 & 1.8 \\
$E_{j}$ & 3 & 3.42 \\
\hline
\end{tabular}

Table 1 Comparison between travel time $T_{j}$, relative fuel consumption $C_{j}^{\text {rel }}$, consumption factor $C_{j}$, relative electrical energy $E_{j}^{\text {rel }}$, and electrical energy factor $E_{j}$ for routes ACB and ADB from the example shown in Fig. 17

The route specific consumption factor $C_{j}$ is obtained with the formula

$$
C_{j}=\frac{L_{j}}{\mathrm{~km}} C_{j}^{\mathrm{rel}}
$$

where $C_{j}^{\text {rel }}$ is read from the macroscopic consumption matrix $M_{C}$. The electrical energy factor $E_{j}$ is calculated analogously, using $E_{j}^{\text {rel }}$ from Eq. 6.

The values of $T_{j}, C_{j}^{\text {rel }}, C_{j}, E_{j}^{\text {rel }}$, and $E_{j}$, are shown in Tab. 1 . It can be seen that while $\mathrm{ADB}$ is the faster route, the alternative route $\mathrm{ACB}$ is more energy-efficient for both conventional and electrical vehicles.

Comparison between most energy-efficient route for conventional and electrical vehicles For a comparison between the most energy-efficient routes for electrical and conventional vehicles, we regard another hypothetical example sketched in Fig. 17. To get from point $\mathrm{E}$ to point $\mathrm{F}$, drivers can take either the direct route $\mathrm{EF}$ or a considerably longer route EGF. We assume that a speed breakdown has occurred on EF leading to oversaturated traffic, while the traffic on route EGF is still undersaturated. Possible values of $V_{j}$, $A_{j}, D_{j}$ and route length $L_{j}(j=\mathrm{EF}, \mathrm{EGF})$ are given in Fig. 17. 


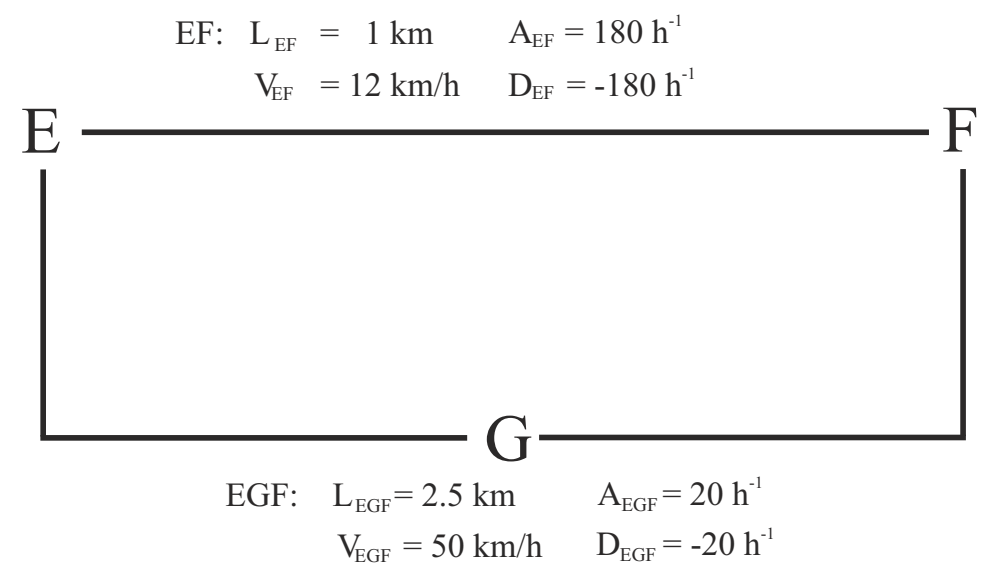

Figure 18 Schematic sketch of a subset of a hypothetical urban road network with two alternative routes $\mathrm{EF}$ and $\mathrm{EGF}$ from point $\mathrm{E}$ to point $\mathrm{F}$

\begin{tabular}{lll}
\hline route $j$ & $\mathrm{EF}$ & $\mathrm{EGF}$ \\
\hline$T_{j}$ & $300 \mathrm{~s}$ & $180 \mathrm{~s}$ \\
$C_{j}^{\text {rel }}$ & 3.1 & 1.1 \\
$C_{j}$ & 3.1 & 2.75 \\
$E_{j}^{\text {rel }}$ & 1.8 & 0.8 \\
$E_{j}$ & 1.8 & 2 \\
\hline
\end{tabular}

Table 2 Comparison between travel time $T_{j}$, relative fuel consumption $C_{j}^{\text {rel }}$, consumption factor $C_{j}$, relative electrical energy $E_{j}^{\text {rel }}$, and electrical energy factor $E_{j}$ for routes ACB and ADB from the example shown in Fig. 18

The resulting values of $T_{j}, C_{j}^{\mathrm{rel}}, C_{j}, E_{j}^{\mathrm{rel}}$, and $E_{j}$, are shown in Tab. 2. EGF, the undersaturated route, is the faster route. However, while EGF is more energy-efficient for a conventional vehicle, the congested route EF is more energy-efficient for an electrical vehicle. This result indicates that the impact of oversaturated traffic on energy efficiency is stronger for a conventional vehicle than for an electrical vehicle.

\section{Conclusions}

In this study of oversaturated city traffic, we have examined the impact of empirical traffic patterns on the energy efficiency of vehicles. Our analysis is based on empirical GNSS data from navigation devices and macroscopic energy matrices obtained by combining real field energy data from vehicles with simulated speed and acceleration profiles. We have obtained the following results.

1. Oversaturated city traffic after speed breakdown commonly consists of synchronised flow patterns (SPs), sequences of moving queues (MQs), and mixtures between SPs and MQs. 
2. The cumulated acceleration is considerably greater for MQs than for SPs.

3. The energy consumption of vehicles increases with increasing cumulated acceleration.

4. Items 2 and 3 mean that the energy consumption of vehicles traversing MQs is considerably greater than the energy consumption of vehicles traversing SPs.

5. The impact of oversaturated city traffic on the energy efficiency of vehicles is stronger for a conventional vehicle than for an electrical vehicle.

6. In an urban road network, the fastest route between two points can be different from the most energy-efficient route.

7. In an urban road network, the most energy-efficient route for a conventional vehicle with a combustion engine can be different from the most energy-efficient route for an electrical vehicle.

These results can be applied in the development of advanced driver assistance systems, in route guidance and in traffic management. The practical applicability of the macroscopic consumption matrices was shown in the research project UR:BAN [58].

Acknowledgements We thank the German Federal Ministry for Economic Affairs and Energy for support in the project UR:BAN (Urban Space: User Oriented Assistance Systems and Network Management, www.urban-online.org). We also thank O. Kannenberg, S. Lorkowski and N. Witte for providing anonymised GNSS probe data from the TomTom company, and T. Schendzielorz, F. Offermann for providing measured energy data from an electrical vehicle and D. Rohatschek for calculating a microscopic empirical energy matrix.

\section{References}

[1] Webster, F.V.: Traffic Signal Settings. Tech. rep., Road Research Laboratory Technical Paper No. 39 (1958)

[2] Newell, G.F.: Queues for a fixed-cycle traffic light. The Annals of Mathematical Statistics 31(3), 589-597 (1960)

[3] Morgan, J.T., Little, J.D.C.: Synchronizing traffic signals for maximal bandwidth. Operations Research 12(6), 896-912 (1964)

[4] Newell, G.F.: Approximation methods for queues with application to the fixed-cycle traffic light. Siam Review 7(2), 223-240 (1965)

[5] Little, J.D.C.: The synchronization of traffic signals by mixed-integer linear programming. Operations Research 14(4), 568-594 (1966) 
[6] Grafton, R.B., Newell, G.F.: Optimal policies for the control of an undersaturated intersection. In: R. Herman, R. Rothery (eds.) Vehicular Traffic Science, pp. 239257. Elsevier, New York (1967)

[7] Robertson, D.I.: TRANSYT: a traffic network study tool. Transport and Road Research Laboratory Report LR 253. Tech. rep., Crowthorne: TRL (1969)

[8] Robertson, D.I.: Traffic models and optimum strategies of control: a review. In: Proceedings of the International Symposium on Traffic Control Systems, pp. 262288 (1979)

[9] Stephanopoulos, G., Michalopoulos, P.G.: Modelling and analysis of traffic queue dynamics at signalized intersections. Transportation Research Part A: General 13(5), 295-307 (1979)

[10] Michalopoulos, P.G., Stephanopoulos, G., Pisharody, V.: Modeling of traffic flow at signalized links. Transportation Science 14(1), 9-41 (1980)

[11] Michalopoulos, P.G., Pisharody, V.: Platoon dynamics on signal controlled arterials. Transportation Science 14(4), 365-396 (1980)

[12] Michalopoulos, P.G., Stephanopoulos, G., Stephanopoulos, G.: An application of shock wave theory to traffic signal control. Transportation Research Part B: Methodological 15(1), 35-51 (1981)

[13] Hunt, P.B., Robertson, D.I., Bretherton, R., Winton, R.: SCOOT-a traffic responsive method of coordinating signals. Transport and Road Research Laboratory Report LR 1014 (1981)

[14] Newell, G.F.: Applications of Queueing Theory. Chapman and Hall, London (1982)

[15] Gartner, N.H.: OPAC: A demand-responsive strategy for traffic signal control. Transportation Research Record 906, 75-81 (1983)

[16] McShane, W.R., Roess, R.P.: Traffic Engineering. Prentice Hall, Englewood Cliffs, NJ (1990)

[17] Dion, F., Rakha, H., Kang, Y.S.: Comparison of delay estimates at under-saturated and over-saturated pre-timed signalized intersections. Transportation Research Part B: Methodological 38(2), 99-122 (2004). doi:10.1016/S0191-2615(03)00003-1

[18] Gartner, N.H., Stamatiadis, C.: Traffic Networks, Optimization and Control of Urban. In: Meyers R. A. (Ed.): Encyclopedia of Complexity and System Science, Springer, pp. 9470-9500 (2009)

[19] Geroliminis, N., Skabardonis, A.: Identification and analysis of queue spillovers in city street networks. IEEE Transactions on Intelligent Transportation Systems 12(4), 1107-1115 (2011). doi:10.1109/TITS.2011.2141991 
[20] Treiber, M., Kesting, A.: Traffic flow dynamics: Data, Models and Simulation. Springer-Verlag Berlin-Heidelberg (2013)

[21] Elefteriadou, L.: An introduction to traffic flow theory. Springer, New York (2014)

[22] Kerner, B.S.: The Physics of Traffic. Springer, Berlin, New York (2004)

[23] Kerner, B.S.: Introduction to Modern Traffic Flow Theory and Control: The Long Road to Three-Phase Traffic Theory. Springer, Berlin, New York (2009)

[24] Kerner, B.S.: Experimental features of self-organization in traffic flow. Physical Review Letters 81(17), 3797 (1998)

[25] Kerner, B.S.: Congested traffic flow: observations and theory. Transportation Research Record: Journal of the Transportation Research Board 1678(1), 160-167 (1999)

[26] Kerner, B.S.: The physics of traffic. Physics World 12(8), 25-30 (1999)

[27] Kerner, B.S.: Physics of traffic gridlock in a city. Physical Review E - Statistical, Nonlinear, and Soft Matter Physics 84(4), 045102 (2011)

[28] Kerner, B.S.: Theory of self-organized traffic at light signal. Tech. rep. (2012)

[29] Kerner, B.S.: The physics of green-wave breakdown in a city. EPL (Europhysics Letters) 102(2), 28010 (2013). doi:10.1209/0295-5075/102/28010

[30] Kerner, B.S.: Three-phase theory of city traffic: Moving synchronized flow patterns in under-saturated city traffic at signals. Physica A: Statistical Mechanics and its Applications 397, 76-110 (2014). doi:10.1016/j.physa.2013.11.009

[31] Kerner, B.S., Klenov, S.L., Schreckenberg, M.: Traffic breakdown at a signal: classical theory versus the three-phase theory of city traffic. Journal of Statistical Mechanics: Theory and Experiment 2014(3), P03001 (2014). doi:10.1088/1742-5468/2014/03/P03001

[32] Kerner, B.S., Klenov, S.L., Hermanns, G., Hemmerle, P., Rehborn, H., Schreckenberg, M.: Synchronized flow in oversaturated city traffic. Physical Review E - Statistical, Nonlinear, and Soft Matter Physics 88(5), 054801 (2013). doi:10.1103/PhysRevE.88.054801

[33] Kerner, B.S., Hemmerle, P., Koller, M., Hermanns, G., Klenov, S.L., Rehborn, H., Schreckenberg, M.: Empirical synchronized flow in oversaturated city traffic. Physical Review E - Statistical, Nonlinear, and Soft Matter Physics 90(3), 032810 (2014). doi:10.1103/PhysRevE.00.002800

[34] Hemmerle, P., Koller, M., Rehborn, H., Kerner, B.S., Schreckenberg, M.: Fuel consumption in empirical synchronised flow in urban traffic. IET Intelligent Transport Systems (2015). doi:10.1049/iet-its.2015.0014 
[35] Geroliminis, N., Kuwahara, M.: The use of telematics to monitor traffic in urban areas: theory and applications. IEEE Conference on Intelligent Transportation Systems, Proceedings, ITSC pp. 748-753 (2008). doi:10.1109/ITSC.2008.4732526

[36] Chow, A.H.F., Santacreu, A., Tsapakis, I., Tanasaranond, G.: Empirical assessment of urban traffic congestion. Journal of Advanced Transportation 48(8), 1000-1016 (2014). doi:10.1002/atr

[37] Döge, K.P.: Ein Beitrag zur videobasierten Verkehrszustandsidentifikation: Automatische Stauerkennung anhand von Live-Kamera-Bildern des Straßenverkehrs. Ph.D. thesis, Technische Universität Dresden (2004)

[38] Kerner, B.S.: A theory of traffic congestion at heavy bottlenecks. Journal of Physics A: Mathematical and General 41(21) (2008). doi:10.1088/1751-8113/41/21/215101

[39] Jun, J., Guensler, R., Ogle, J.: Smoothing methods to minimize impact of global positioning system random error on travel distance, speed, and acceleration profile estimates. Transportation Research Record: Journal of the Transportation Research Board (1972), 141-150 (2006)

[40] Kerner, B.S.: Cumulated vehicle acceleration. Traffic Engineering and Control 55(4), 139 - 141 (2014)

[41] Watson, H.C.: Effects of a wide range of drive cycles on the emissions from vehicles of three levels of technology. Tech. rep., No. 950221. SAE Technical Paper (1995)

[42] Koller, M., Hemmerle, P., Rehborn, H., Hermanns, G., Kerner, B.S., Schreckenberg, M.: Increased Consumption in Synchronized Flow in Oversaturated City Traffic. In: 10th ITS European Congress, Helsinki, Proceedings (2014)

[43] Koller, M., Hemmerle, P., Rehborn, H., Kerner, B.S.: Traffic Phase Dependent Fuel Consumption. In: Proc. 11th Conference on Traffic and Granular Flow. Nootdorp, the Netherlands (2015)

[44] Koller, M., Hemmerle, P., Rehborn, H., Kerner, B.S., Schreckenberg, M., Hermanns, G.: Mehrverbrauch im gestauten Stadtverkehr. Straßenverkehrstechnik 59(12), 820 824 (2015)

[45] Koller, M.: Kraftstoffmehrverbrauch auf Basis dynamischer Verkehrslagen. Ph.D. thesis, Eberhard Karls Universität Tübingen (2015)

[46] Akcelik, R.: Progress in Fuel Consumption Modelling for Urban Traffic Management. Tech. rep., Australian Road Research Board (1983)

[47] Kerner, B.S., Klenov, S.L.: A microscopic theory of spatial-temporal congested traffic patterns at highway bottlenecks. Phys. Rev. E 68(3), 036130 (2003) 
[48] Kerner, B.S., Klenov, S.L.: A microscopic model for phase transitions in traffic flow. Journal of Physics A: Mathematical and General 35(3), L31-L43 (2002)

[49] Kerner, B.S., Klenov, S.L.: Spatialtemporal patterns in heterogeneous traffic flow with a variety of driver behavioural characteristics and vehicle parameters. Journal of Physics A: Mathematical and General 37(37), 8753-8788 (2004)

[50] Kerner, B.S., Klenov, S.L.: Phase transitions in traffic flow on multilane roads. Physical Review E - Statistical, Nonlinear, and Soft Matter Physics 80(5), 056101 (2009)

[51] Kerner, B.S., Klenov, S.L.: A theory of traffic congestion at moving bottlenecks. Journal of Physics A: Mathematical and Theoretical 43(42), 425101 (2010)

[52] Hermanns, G., Hemmerle, P., Rehborn, H., Koller, M., Kerner, B.S., Schreckenberg, M.: Microscopic Simulation of Synchronized Flow in Oversaturated City Traffic: Effect of Drivers Speed Adaptation. Transportation Research Record: Journal of the Transportation Research Board 2490, 47-55 (2015)

[53] Nesamani, K.S., Chu, L.Y., McNally, M.G., Jayakrishnan, R.: Estimation of Vehicular Emissions by Capturing Traffic Variations. Atmospheric Environment 41(14), 2996-3008 (2007)

[54] Barth, M., Boriboonsomsin, K.: Real-world CO2 impacts of traffic congestion. Transportation Research Record: Journal of the Transportation Research Board 2058, 163-171 (2008)

[55] Boriboonsomsin, K., Barth, M., Zhu, W., Vu, A.: ECO-Routing Navigation System based on Multi- Source Historical and Real-Time Traffic Information. IEEE Transactions on Intelligent Transportation Systems 13(4), 1694-1704 (2012)

[56] Barth, M., Boriboonsomsin, K.: Energy and emissions impacts of a freeway-based dynamic eco-driving system. Transportation Research Part D: Transport and Environment 14(6), 400--410 (2009)

[57] Abousleiman, R., Rawashdeh, O.: Electric vehicle modelling and energy-efficient routing using particle swarm optimisation. IET Intelligent Transport Systems (2015). doi:10.1049/iet-its.2014.0177

[58] Ur:ban - urbaner raum: Benutzergerechte assistenzsysteme und netzmanagement (urban space: User oriented assistance systems and network management). URL http://urban-online.org/de/urban.html 